\title{
6 \\ Epidemiology, epidemics and autism as a global health crisis
}

\author{
Children's rights in global context
}

The 1970s and 1980s had brought important changes to the structure of children's rights in Britain that had repercussions around the world. At the same time, Margaret Thatcher's model of economic policy that encouraged privatisation of public services and a reduction in public spending, together with tax cuts, was a prototype that was either emulated or scorned across the world. Together with US president Ronald Reagan (1981-89), Thatcher came to represent a model of social and economic policy that could dismantle social welfare systems whilst simultaneously building them up under new neoliberal models of engagement. As historian Ben Jackson has argued, her success was predicated on the development of an 'archipelago' of 'think-tanks' established in the post-war period in Britain and internationally with support by interested donors, who developed an international model of neoliberalism as a valid political philosophy. ${ }^{1}$ The 1980 s saw this political model thrive and it continued to hold weight in British politics and elsewhere in the 2000s through the creation of Tony Blair's 'third way' and beyond.

Nikolas Rose has questioned whether neoliberal policies of marketisation and privatisation have caused the 'death of the social', leading to a form of economic government in which active entrepreneurial citizens are encouraged to model their own lives through engaging in a market for welfare products such as educational advantage and health status. ${ }^{2}$ The introduction of neoliberal interventions into social welfare has definitely led to a radical restructuring of the conception of children's rights. The growth of a 'neoliberal' model of citizenship helped 
frame the Children Act 1989 through the idea that children were full individuals and not just appendages to their parents, and therefore involved in decision-making about their own welfare. ${ }^{3}$ However. the place of children within this new network of 'post-social' technologies is complicated by the fact that they still occupy a position where they may be 'in need of care and protection' by the state. Within earlier social welfare policies, tensions had always existed because children were subjects of the state yet also subjects of their parents. Harry Hendrick has argued that the 1980s saw these widespread tensions finally overcome, as the construction of true individualised approaches to childhood began to crystallise. ${ }^{4}$ One thing is clear, it is within these new models of children's rights that new prototypes of disability rights began to take shape. It is also within this new model that the concept of autism was adopted widely as a global category and an international model for thinking about individual children's atypical development.

In the same year that the Children's Act was passed in Britain, the United Nations issued a Convention on the Rights of the Child. The 1989 Convention was unanimously adopted by the UN General Assembly and initiated an international agreement on child rights that was the first of its kind, and which replaced all non-binding international declarations on child rights that had focused on children as passive recipients of care and charity. The creation of the 1989 Convention was the outcome of proliferating international agreements on human rights that had sprung from the UN's Universal Declaration of Human Rights in 1948. Many theoretical debates had blossomed in the 1960s and 1970s in Europe and the USA on whether or not children's rights included 'pupil power' to challenge teachers, or complete autonomy from parents, and whether this meant they were in opposition to those of adults. ${ }^{5}$ It took the growing threat of unrestrained neoliberal ideologies in the 1980s to push for an international treaty that would clarify what, exactly, child rights were, and to ensure that they were implemented.

It is in the context of these radical changes in the construction of child rights that the British model of autism came to be adopted across the world as part of a model legal and psychological framework model for recognising both disability rights and children's rights. This chapter explores how British epidemiological research on autism in the 1960s and 1970s came to define global attempts to analyse and understand 
what, exactly, autism is. It argues that these changes have been associated with wider global changes relating to the definition and construction of children's rights. Studies of autism have now almost become status symbols, and demonstrations of an advanced neoliberal approach to child rights, within the developing world.

\section{Victor Lotter's journey to Africa and the globalisation of the second autism}

After Lotter conducted the first epidemiological study of autism in 1966, he became increasingly interested in whether his definition of autism could be applied in a global context. Discussions and concerns over the international applicability of psychiatric concepts drove this fascination. In addition, cultural diversity was rapidly becoming a feature of post-colonial London in the 1960s and 1970s, as immigration from former colonies increased rapidly. By 1981, the London population of 6.6 million included more than one in six people born outside the UK, including 634,000 from Asia, Africa and the Caribbean. ${ }^{6}$ This growing international community was of interest to many child psychiatrists. Furthermore, increasing numbers of doctors from the New Commonwealth were also immigrating and this encouraged debate within the medical community itself. Aubrey Lewis's insistence that all psychiatric trainees spend six months training in child psychiatry encouraged this debate. By the 1980s, international doctors and social workers were regularly training and working at the Brixton Child Guidance Clinic and by 1984, fortnightly meetings were held on 'racism awareness and multi-ethnicity.7 Some researchers, including Rutter, attempted to tackle cultural differences head on in the 1970s. ${ }^{8}$ The field of 'cross-cultural' psychiatry became established internationally during this period. ${ }^{9}$ However, by and large, researchers in child psychiatry treated international diversity as a challenge to the robustness of their concepts.

In the 1970s, Victor Lotter, the pioneer of autism epidemiology, decided it was time to challenge the durability and stability of the new concept of autism by leaving the anonymous suburbs of Middlesex and heading to Africa, embarking on an extensive tour of several major cities to see if he could find cases of autism in Accra, Ghana; Lagos, Nigeria; 
Nairobi, Kenya; Lusaka, Zambia; Salisbury, Rhodesia; and Cape Town, South Africa. ${ }^{10}$ This was the first attempt to make autism a global category and to use epidemiology to raise questions about the cultural specificity of the condition. At the Third Pan-African Psychiatric Conference in 1972, two Nigerian doctors, C. I. Longe and T. Asuni, had described four cases of 'infantile autism' in Nigerian children, claiming the condition was more common in children from the upper-middle classes. Lotter thought that better social and epidemiological methods were required in order to test such a claim. His aim was to survey children already classed as 'mentally handicapped' in all the African regions he visited and to see how many of them were 'autistic' according to the new criteria. His overt goal was to test the claim that all autistic symptoms were universal in order to see how far the environment impacted on symptomatology. As he put it, because 'the psychological environment for children is maximally different (in unspecified ways) from that in technologically developed countries', a 'cross-cultural' study could reveal how far environmental factors were important. It could also silence the speculation that autism did not actually 'exist' in Africa, pointing out that his extensive studies proved that 'autistic children "undoubtably exist" there."

During Lotter's major tour, he examined 1,300 children known to local authority services, most of whom were institutionalised, finding 'autistic-like behaviour' in only thirty of them. According to Lotter, only nine of them were found to be 'autistic according to Western criteria. Based on his own observations and discussions with African doctors, he reported that in African institutional populations there were, apparently, far fewer children who engaged in 'elaborate ritualistic activities involving objects', and other repetitive movements such as flapping, rocking and headbanging, than was the case in Western institutional populations. This was significant if autism was to be diagnosed according to behavioural criteria only, as he had defined it in his 1966 study. Lotter acknowledged that this was not a full epidemiological survey, but he argued that the proportion of mentally handicapped children that fitted his behavioural criteria for autism was only 0.7 per cent in his African sample but between 5 and 8 per cent in his Middlesex sample. ${ }^{12}$ He speculated that this may be due to better rates of infant survival in Britain, but acknowledged that the findings were as yet inconclusive. ${ }^{13}$ Lotter's findings did not explore cultural difference in 
any detail, nor did they encompass the post-colonial reflections on self-identity, raised by scholars such as Frantz Fanon, that were reaching a wide audience by the $1960 \mathrm{~s} \cdot{ }^{14}$ An important part of the British epidemiological model was that it insisted on the universality of its concepts.

One thing that Lotter's study did reveal was that the level of provision for the treatment of childhood psychiatric and psychological problems was very limited. Scant administrative systems also meant that very little was known about the occurrence of all forms of 'mental handicap or behaviour disorders generally'. Furthermore, limited resources meant that priority was often given to what were 'quantitatively more pressing developmental problems such as malnutrition, infectious diseases, blindness and deafness. ${ }^{15}$ These were strong findings of health inequalities, and said a lot about the lack of disabled children's rights. Lotter's work therefore encouraged international epidemiological studies of autism, making the argument that such studies would provide the key to discovering the true nature of this elusive and complex psychological definition.

In fact, international epidemiological studies of autism in the aftermath of Lotter's first 1966 epidemiological study of autism in Middlesex had been remarkably scarce, and most had reported very low rates. Most of these were not full epidemiological surveys but merely based on clinic populations, such as the 1970 study by Danish researcher Birte Hoeg Brask, who posited a rate of 4.3 per 10,000 in Aarhus; a 1970 study by US doctor, Darold Treffert, who gave a rate of 2.5 per 10,000 in Wisconsin; and a series of studies in different districts in Japan in the early 1970 s that gave rates varying from 0.9 to 5.02 per $10,000 .{ }^{16}$ None of these studies used the concept of autism to try to reframe wider concepts of child development as Lorna Wing and Judith Gould's study had done. It was only after the publication of Wing and Gould's landmark epidemiological study in 1979 that international epidemiological studies of autism began to thrive. Furthermore, it was only after this that reported rates of autism began to increase. These increases were associated with a widespread change in the description of the condition that had only materialised in Wing and Gould's work. They were supported by the diagnostic engine of the DSM, which was encouraging critical reflection and discussion on the global applicability of psychiatric concepts. 


\section{International child psychiatry and psychology}

International agreements on child rights were paralleled by international agreements on the definition and description of psychological conditions in children. This is perhaps unsurprising given the correlation between individual child rights and psychological discourse in Britain that was mapped out in the previous chapters. Yet, now, the recognition of autistic spectrum conditions as fundamental to ensuring universal child rights has been adopted on a global stage. Since the 1960s, Michael Rutter had been active in trying to achieve an international consensus on the definition of psychological conditions in children. The psychiatric diagnoses first published in the sixth edition of the International Classification of Diseases (ICD) in 1949 had not been widely accepted. ${ }^{17}$ Within the subdiscipline of child psychiatry, there was even less consensus amongst practitioners, as many preferred to work with psychoanalytic concepts, and this persisted into the 1970s. Rutter's 'multi-axial' system helped to achieve some consensus as it acknowledged 'psychosocial' factors in its diagnostic coding system, thereby quelling the anxieties of child psychoanalysts and psychologists who wanted to resist purely neuroscientific models. ${ }^{18}$ The aim of Rutter's system was to encourage further research that used the statistical method in order to clarify phenomenological problems in psychiatry. His multi-axial model of diagnosis was included in the Diagnostic and Statistical Manual (DSM) in 1980. It was only after the publication of this manual that detailed international discussions, debates and agreements on the definition of 'psychiatric disorders' began to crystallise, thereby enabling diagnoses that could be employed in international studies. ${ }^{19}$ It was also the DSM that encouraged the wider use of the term 'disorder' when describing psychological or psychiatric conditions generally.

Historians, psychiatrists and many others have argued that the publication of the third edition of the DSM (DSM-III) in 1980 was a definitive moment in the history of psychiatry. This is primarily because Robert Spitzer of Columbia University, USA, and the 'task-force' who were employed to revise earlier versions of the manual claimed they had produced a radically new scientific textbook that defined symptoms objectively in the tradition of Kraepelin. Most importantly, the manual created a common language that could be used by various disciplinary groups ranging from psychiatrists, social workers and psychologists 
to researchers, insurance companies and pharmaceutical companies. This helped to generate its success in the USA where it was born, and then also elsewhere where such common agreement was required. ${ }^{20}$ The hype surrounding the publication helped to ensure its widespread reception and encouraged much critical debate. ${ }^{21}$

Rutter's work was also fundamental in shaping a lot of the child psychiatric definitions. The classification of 'infantile autism' employed in DSM-III was derived directly from a definition drawn up by Rutter in 1978, namely:

(1) an onset before the age of 30 months,

(2) impaired social development that has a number of special characteristics and is out of keeping with the child's intellectual level,

(3) delayed and deviant language development that also has certain defined features and is out of keeping with the child's intellectual level, and

(4) insistence on sameness, as shown by stereotyped play patterns, abnormal preoccupations, or resistance to change. ${ }^{22}$

It was via the DSM that British models of autism, developed in the legal, political and social context of 1970 s post-Seebohm Britain, would come to dominate international definitions of autism.

In particular, DSM-III helped to consolidate the new model of autism as an absence of hallucination, delusion, fantasy life and an inability to play, imagine and creatively represent objects in the mind. Although it had figured prominently in earlier versions of the text, the category of 'childhood schizophrenia' was completely written out of DSM-III (1980). Instead, DSM-III introduced the new category of 'pervasive developmental disorders', a diagnosis that included four subcategories: namely, 'infantile autism', 'childhood onset pervasive developmental disorder', 'residual autism' and an 'atypical form'. The idea that autism was one of a range of related conditions was thus set in stone. At the same time, the original concept of autism, which had previously played an important part in the diagnostic criteria for adult schizophrenia, was completely removed from the diagnostic criteria for schizophrenia in adults. Spitzer argued that this was due to its unreliability as an observable symptom. ${ }^{23}$ But this effectively meant that 'autism', although 'unreliable' as a key concept in the diagnosis of adult schizophrenia, was then implemented as a category within 'pervasive developmental disorders 
of childhood' because it was considered reliable when applied to children under a wide umbrella of other psychological disorders - now termed 'pervasive developmental disorders'. It was regarded as reliable because of the growing paraphernalia for testing autism in children and the fact that this new concept of autism, the 'second' autism, now had a completely differently meaning. The fact that the second autism assumed its position as part of a wider framework for thinking about atypicalities in child development was not new. What was new was that autism now meant the opposite of what it had meant before. Throughout the 1980s and 1990s, the second 'autism' would be the one that took centre stage across the globe. It did so via a web of epidemiological studies that simultaneously disseminated, reproduced and multiplied this model.

In the early 1980s, many clinicians criticised DSM-III criteria for 'infantile autism', based on Rutter's work, because they found it too restrictive. ${ }^{24}$ Many clinicians who had been diagnosing 'childhood schizophrenia', 'psychosis' and 'autism' for some time found that their cases no longer qualified. This included clinicians who were generally psychoanalytically inclined and who had employed the terms 'autism, 'childhood schizophrenia' and 'childhood psychosis' in a rather general way due to the influence of Klein, Bender and others. It is thus unsurprising that they found Rutter's criteria restrictive. In a formal evaluation of the criteria in the USA, many practising child psychiatrists found the criteria unworkable. ${ }^{25}$ For example, a meeting of autism researchers in 1984 expressed concerns about the classification of infantile autism and, in fact, all 'pervasive developmental disorders', and called for a more logical approach to classification. ${ }^{26}$ In the model of the DSM, no approach to the classification of childhood developmental conditions could be more logical than Wing's approach, which took a complete population of children and defined the total population using behavioural criteria. Wing's definition was coming to be acclaimed internationally. Her astute, yet subtle, creation of a comprehensive model of inclusive human relations was lapped up by behaviourists, government officials and others struggling to create some way of conceptualising social development in children now that psychoanalytic models were being widely challenged and neoliberal ideologies were stripping the 'social' of its association with welfare and national rights. 
Although the DSM was a US publication, British researchers were shipped over in order to settle the argument over autism. This should not be a surprise as these British researchers had been those who were most focused on developing robust statistical tools for measuring autism epidemiology since the 1960s. Michael Rutter had a major public debate with Lorna Wing at the committee meeting. This focused on the DSM-III requirement that autism could only be diagnosed if it started in the first thirty months of life. Rutter thought this was essential as it encouraged research into different clinical groups with different aetiologies and encouraged detailed developmental histories, but Wing did not agree. She argued that removing the age of onset would encourage research into aetiology because autism would be defined descriptively, rather than categorically, in a similar way to mental retardation, and this would encourage interest into its origins. Wing's argument that the definition needed to encourage research within new epidemiological and statistical sciences of mental disorder was the most compelling at a time when such sciences were in their infancy. The concept of autism offered so much promise for setting these sciences straight because it was still regarded by many as a core concept within theories of child development. Just as the first autism served as an organising concept within earlier models of infantile thought and its unconscious or unknown elements, the second autism promised to provide a baseline or reference model for the statistical sciences in psychiatry. It is for this reason that so much controversy existed around its entry into the DSM and for this reason that it has become such a popular diagnosis.

The publication of DSM-III had led to a lot of discussion about the new collection of 'pervasive developmental disorders' and many began to use that term as a synonym for 'neurodevelopmental disorders'. AS discussed earlier, 'Neurodevelopmental' was a term that had been in use since the 1970s to describe all kinds of research on the brain development of infants, although its use to describe a type of 'disorder' grew rapidly with the publication of DSM-III. ${ }^{27}$ There was a growth in the use of all these terms and an increasing lack of clarity about what they all meant. Autism was sometimes used interchangeably with 'pervasive developmental disorders', which increased confusion. In 1983, Martha Denckla from the US National Institute of Neurological and Communicative Disorders and Stroke organised a major conference on the 'diagnosis of autism and related disorders', bringing together 
child psychology professionals from across the USA, such as Marian K. DeMeyer from Indiana, Fred Volkmar from Yale and Eric Schopler from North Carolina, along with Lorna Wing from the UK. There was a consensus that the DSM-III definition of autism was not yet a sufficient classification, particularly for epidemiological studies, and that researchers were clearly interested in the much broader spectrum of 'pervasive developmental disorders. ${ }^{28}$ One major criticism of Rutter's narrow definition of autism was that it was not good for the development of psychiatric epidemiology that, in the spirit of the DSM, was now placing several other conditions such as 'depression' and 'bipolar disorder' on 'spectrums' or 'scales. ${ }^{29}$ In the process of denouncing the first autism, it was agreed that researchers should adopt an 'atheoretical' view but should describe 'social and non-verbal communicative skills', and possibly 'symbolic imaginative play skills too', when describing their chosen subjects. This would help to build up a new understanding of social engagement and imaginative play based on the mass observation and calculation of children's behaviour, rather than psychoanalytic ideas about infantile fantasy. ${ }^{30}$

DSM-III-R criteria for autism were drawn, almost word for word, from Wing's definition of the 'triad', namely: 'A. Qualitative impairment in reciprocal social interaction', 'B. Qualitative impairment in verbal and nonverbal communication, and in imaginative activity' and 'C. Markedly restricted repertoire of activities and interests'. Each part of the triad was then elaborated with sixteen item descriptions and illustrations: for example, 'qualitative impairment in social interaction' could be manifested as 'marked lack of awareness of the existence of feelings of others (e.g. treats a person as if he or she were a piece of furniture; does not notice another person's distress; apparently has no concept of the need of others for privacy)'. Autism could be diagnosed if eight of the total sixteen items were present across the entire triad. ${ }^{31}$ There was some concession to Rutter as age of onset still had to be recorded for research purposes. ${ }^{32}$ The publication of DSM-III-R was a major turning point that enabled the spread of Wing and Gould's model of epidemiology and autism, and galvanised teams of researchers to investigate. The seeds were then fully sown for increased observations and diagnoses of autism, which was now a descriptive term once more. In 1989, ICD 10 followed the DSM in listing autism as one of several 'pervasive developmental disorders', drawing from Wing's definition. ICD 
10 also included Wing's category of 'Asperger's syndrome', which further propagated her conviction that stereotyped play signalled a lack of imaginative abilities and further expanded the cases in which the diagnosis could be applied.

The reason that psychologists from Britain were so dominant in directing international definitions of autism was because they had consistently drawn upon statistical and epidemiological models to define autism that had provided them with a set of criteria that were not defined by cultural or social specificities. The setting of post-colonial London, and Lotter's research in Africa, had strengthened this acultural, ahistorical and, ultimately, very open definition of autism that the global community went on to adopt with such enthusiasm. This second autism was an ideal concept upon which to build a new model of human relations, of sociality and relationships that could support new models of child rights within a neoliberal model of social entrepreneurialism. It provided it with statistical accuracy and mathematical precision, qualities much valued in an era of financial speculation and globalisation. Lorna Wing's 'style of reasoning' that viewed autism as an epidemiological entity defined by the absence of imagination and creativity, and the presence of scientific calculated precision, was the perfect acultural construction of childhood psychological development. Autism's success must be viewed within this context.

\section{International development and the first wave of epidemiological studies}

It was after Wing and Gould's 1979 epidemiological study that reported rates of autism began to increase. During the 1980s, Victor Lotter's attempts to instigate discussion about different rates of autism in different countries were beginning to bear fruit. In 1984, Victor Sanua from the Department of Psychology at St John's University, New York, had written to child psychiatrists across the world asking for their opinions on the question 'Is infantile autism a universal phenomenon?' The Chairman of the Department of Psychology of the University of Sao Paulo, Dr Lourencao Van Kolck, had replied: 'Really, autism is a rare disease in our country'. Dr Chakraborty, Professor of Psychiatry at the R. G. Kar Medical College of Calcutta had apparently concurred that 
cases were also rare in India, and Dr Mohammed Fakr el Islam, who practised widely in the Middle East, had argued that 'cases of infantile autism are very few in this part of the world'. There was no way of validating such claims, or even confirming that everyone was actually talking about the same thing. However, Sanua concluded that infantile autism appears to be an illness of Western Civilization, and appears in countries of high technology, where the nuclear family dominates. ${ }^{.33}$ Sanua had support for this in the theory of Nikolas Tinbergen, which had drawn upon a form of anthropological reflection on Western civilisation as the cause of autism, a theory that had quite a short shelf life given wider changes in the spread of neoliberalism and the critique of evolutionary models of social progress. The idea that autism was a disease of western civilisation looked increasingly shaky as parent groups started to form and demand that autism be investigated properly in their countries and that international children's rights be adhered to.

In the early 1970s, Peter Venables, the doyen of psychophysiological research who had moved from the Institute of Psychiatry to Birkbeck, London, had established a major longitudinal study of child health and development following a meeting with the World Health Organization (WHO) Scientific Group of Neurophysiological Methods. ${ }^{34}$ The WHO Scientific Group recommended that any longitudinal study should be conducted in a developing country and that it should investigate three-year-old children, establish nursery schools for these children and use psychophysiological research to identify their risk factors for later mental illness. Mauritius was chosen as the destination as it was a small island with low emigration. It was also a former British colony, granted independence in 1968. This study established by Venables became a model for health epidemiology in developing countries and a symbol of international collaboration. ${ }^{35}$ It later received funding from multiple health research bodies from Denmark, Britain and the USA. ${ }^{36}$ By the late 1970 s, the WHO study was providing reliable information on international child health and was frequently emulated as a model for international research. It defied theories of child development framed by unhelpful models of evolutionary progress and presented an exemplary approach to international research that was widely respected.

Building on Venables' successes in international collaboration, autism researchers began to develop new ways to research autism 
across national boundaries and to use this international research to develop new hypotheses about both the condition and the importance of its recognition in ensuring children's rights. For example, the Society for Autistic Children in Britain teamed up with parental organisations and research communities across the continent to form Autism Europe in 1976. The initial aim was to draw together the expertise of European researchers. However, their goals quickly evolved. In 1983, the International Association Autism Europe (IAAE) was established to create a forum that also valued parental opinion and to create a space where parents and professionals could 'meet and overcome the problems that differences of health, education, legal and social systems create. This enabled Europe-wide comparisons in social care and research approaches and the sharing of databanks and information, and also deliberately encouraged changes in the law to acknowledge the specific rights of people diagnosed with autism. ${ }^{37}$ After the formation of IAAE, the role of parents and autism self-advocates became part of most conferences.

In 1989 Autism Europe presented a charter of rights for autistic people based on the United Nations' Declaration on the Rights of Mentally Retarded Persons (1971) and the Rights of Handicapped Persons (1975). The charter was presented at the 1992 Autism Europe Conference. It included the right of people with autism to live independent and full lives to the limit of their potential', 'the right of people with autism to sexual and other relationships, including marriage, without exploitation or coercion' and 'the right of people with autism to freedom from fear or threat of unwarranted incarceration in psychiatric hospitals or any other restrictive institutions.' The declaration also stated that 'at least one million citizens within the EU are affected by autism which is a mental disability. ${ }^{38}$ This was an important document as it acknowledged that autistic children grew up into autistic adults and therefore expanded autism rights across a wider age range. The efforts of Autism Europe to bring together European professionals and parents was obviously facilitated by the growing social and economic links created across Europe in the 1980s, in particular the signing of the Single European Act in 1986, leading to the creation of the Single Market in 1993. The third Autism Europe Conference was held in Hamburg in 1988, with a strong focus on education programmes designed specifically for autistic children, including computer-assisted learning. ${ }^{39}$ 
In the same year, Autism Europe established LINK, a project to publish important international research, collaborative research and press reports three times yearly to keep all those in the international field up to date.

However, it was not just European countries that were becoming interested in this new measure of childhood disability and were attempting to use it to redefine conceptions of child rights and human rights. By the early 1990s, societies specifically for autistic children had been created in forty countries, among them countries as diverse as Australia, Brazil, Bulgaria, Germany, Iceland, India, Japan, Russia and Trinidad and Tobago. ${ }^{40}$ By the early 2000s, these organisations had spread to over eighty countries across the globe including Sri Lanka, Lithuania, Lebanon, Mexico and Nigeria. ${ }^{41}$ All of these organisations worked with international definitions ultimately derived from Wing's epidemiological study of social impairments. The late twentieth and early twenty-first centuries have also witnessed a major proliferation of research studies on autism diagnosis, epidemiology, genetics and more. These are conducted in research institutes across the world, as well as via collaborative international research.

Autism, as a globalised category, is important because it has provided unique rights to those diagnosed with it and has also enabled parents of children diagnosed with autism to become part of a wider network of global institutions interested in the treatment of developmental conditions in children generally, as well as in providing financial assistance and support. Unlike mere 'subnormality' or 'intellectual impairment', autism was a topic that literally 'captured the imagination' and encouraged international researchers and parents to come together and collaborate in order to generate new models of early infantile thought.

British epidemiological definitions of autism, developed by Maudsley-trained researchers, were becoming increasingly globalised and were being used in epidemiological studies across the world. Such studies became increasingly coveted as status symbols in the developing world. Without epidemiology, child psychiatrists and psychologists had limited influence as they could not engage in international debates and research. The first epidemiological studies following Wing's work were conducted primarily in Europe. In the 1980s, Christopher Gillberg began studies of mental retardation and autism in the 
total population of Gothenburg, Sweden. Whilst he found only 3.9 per 10,000 to have typical autism, he reported an identical rate to Wing and Gould's measure of the 'triad of impairments' in a total population at 21 per $10,000 .^{42}$ This helped to support Wing's methodology and the general idea of a wider 'spectrum' of neurodevelopmental disorders associated with autism.

As more international researchers became interested in autism, it became evident that unique national approaches were affecting reported results, even though Wing and Gould's work provided the working model. In Canada, for example, a 1987 study by Susan Bryson from Dalhouisie University, Nova Scotia, found a rate of 10 per 10,000 ostensibly using Wing and Gould's definition of autism. However, Bryson had not included 'asocial severely retarded' in her sample, as Wing and Gould had done. Bryson argued that her definition of autism was thus closer to the 'nuclear' form, for which a rate of 4-5 per 10,000 was usually found. She claimed her increased figures were due to the fact that children who would otherwise have been overlooked as being within a typical or normal range of development were now being included because they demonstrated the 'triad of impairments' to a very minor degree. ${ }^{43}$ This was a slightly different take on Wing and Gould's approach and obviously had an impact on the final reported data and how it could be interpreted.

In France, psychoanalytic definitions of autism remained stronger than elsewhere, thus a different interpretation emerged.$^{44}$ In 1989 , P. Cialdella from the Hôpital Bellevue, Saint Etienne, and M. Mamelle from the Institut National de la Santé et de le Recherche Médicale conducted an epidemiological study that integrated psychoanalytic interpretations. Cialdella and Mamelle liked Wing's 'continuum hypothesis' within the framework of pervasive developmental disorders. Interestingly, however, and in a uniquely French fashion, they argued that it expanded the possibilities for diagnosing 'child psychosis' and schizophrenic symptomatology in children, arguing that pervasive developmental disorders were identical to 'what French psychiatrists call child psychosis'. In their epidemiological count of 10.8 per 10,000 , they included children with 'schizophrenic features' such as 'listening attitudes', thought to be 'related to hallucinations', as well as 'incongruent laughing or crying', apparently not heeding the reservations expressed by Lotter, Rutter and Wing on the problems of 
including symptoms of hallucination and delusion in children in an epidemiological survey. ${ }^{45}$

In Japan, Toshiro Sugiyama of Aichi Prefectural Colony and Tokuichiro Abe of Shizuoka Prefectural Hospital conducted an epidemiological study based on Wing and Gould's definitions, finding a rate of 13 per 10,000. However, they argued that it was not entirely clear what separated 'typical' autism from wider 'social impairment' in Wing's work, or what separated children with autism from those with 'autistic features' in Lotter's study. They also had several questions about what diagnosis a child should receive if they had 'autism' at age two and then lost it by age three, a question that Western researchers had not thought relevant. ${ }^{46}$ Diagnostic criteria did not always travel easily, but this merely encouraged more debate about how Wing and Gould's definitions could be refined.

By the late 1980s, it was becoming apparent that researchers in different countries, and even different regions, were giving very different figures on the prevalence of autism and different interpretations of what autism was. Gillberg's continued studies on the rate of autism in Sweden found regional variations as well as increases over time. A 1986 epidemiological study of 'autism and autism-like' conditions in children aged $2-11$ years in Gothenberg found a rate of 6.6 per 10,000, although Gillberg pointed out that this did not include children with 'autistic traits' and 'autistic spectrum disorders' or the 'triad of impairments' and that inclusion of such children would have raised the reported levels. ${ }^{47}$ However, Gillberg claimed he was finding different rates of autism in Sweden, pointing out in 1991 that in one area of Gothenberg, autism had increased in prevalence per 10,000 from 4.0 in 1980 to 7.5 in 1984 and 11.6 in 1988 . After building up such a comprehensive picture of rates of the new 'total population definition of autism', Gillberg felt confident enough to use these epidemiological studies to make hypotheses about causation, raising questions about maternal age and the higher diagnoses of autism in immigrant populations that, he argued could be due to lower levels of prenatal, perinatal and postnatal care for women who had given birth in developing countries, among other things. ${ }^{48}$ All of this was speculative, but then autism epidemiology inherently encouraged speculation. 
Measuring the second autism

As Rhodri Hayward has pointed out, the development of the post-war 'statistical psyche', compounded by the publication of DSM-III, encouraged application of numerous psychiatric scales to measure psychiatric conditions such as depression, anxiety, bipolar disorder etc. This has led to a proliferation of measuring scales, such as the Hamilton scales for anxiety (1959) and depression (1960) and Eysenck's scales for personality. ${ }^{49}$ This encouraged the expansion of psychiatric categories, or what psychiatrist Peter Kramer has termed 'diagnostic bracket creep', encouraging other minor variants of each condition to be lumped into one wider psychiatric label..$^{50}$ Psychiatric categories, which at first defined only a small group of individuals, could be expanded to include increasing numbers of people who had fewer and fewer symptoms of the original condition. In the case of major depression, Kramer argued that it was primarily the introduction of Prozac that stimulated increasing diagnoses. ${ }^{51}$ In fact, in most instances, this 'diagnostic bracket creep' has been associated with increased production of pharmaceuticals designed to target psychiatric conditions, as described astutely in David Healy's The Anti-depressant Era (1997) and The Creation of Psychopharmacology (2002). However, in the case of autism, the growth in diagnosis had absolutely nothing to do with pharmaceutical products. This was thus a unique kind of 'diagnostic bracket creep' that was associated with concerted attempts by clinical and educational psychologists to criticise apathy and ignorance regarding the presumed 'ineducability' of groups of children, as described in Chapter 5. It was also part of a concerted effort to develop new tools and measuring scales that could be used instead of intelligence tests and could therefore generate a more inclusive model of variations in human development and establish a new model of child rights and disability rights.

Whilst Hermelin and O'Connor, Frith and Baron-Cohen had begun to construct the basis of a way to define and measure social development as opposed to intellectual development in children, it was the ultimate social science and statistical entrepreneur, Rutter, who first designed an extremely successful international instrument for measuring autism. Following the changes that were made in DSM-III-R, Rutter quickly began to work on a new diagnostic instrument that 
could be used to identify cases, now acknowledging that the category had been expanded to include children who developed the complete picture of 'autism' after the age of thirty-six months. In an effort of international collaboration, Rutter and Ann Le Couteur from the Medical Research Council Child Psychiatry Department at the Institute of Psychiatry teamed up with Catherine Lord from the Department of Pediatrics at the University of Alberta, Canada, to develop the Autism Diagnostic Interview (ADI), 'a new standardised investigator-based tool for use in the differential diagnosis of pervasive developmental disorders. ${ }^{52}$ In his attempt to distinguish the ADI from intelligence tests, Rutter always emphasised the necessity of differentiating between immaturity associated with low mental age and what he termed the 'developmental deviance' that is part of autism. As Rutter and Eric Schopler described it, 'impaired language and socialisation is found in many disorders (especially general mental retardation), but the particular patter of deviance found in autism is distinctive to that syndrome.53 This was an important distinction because the ADI did not focus only on the ability to function socially, but rather on age deviations from normal social interaction. In fact, the ADI highlighted the separation of delay from deviance by paying a lot of attention to the 4-5 age period where this was easiest to isolate.

A number of observational scales for 'autism' had been designed in the late 1970s and early 1980s, most issuing from the USA, creating a panoply of abbreviations: BRIAAC, CARS, BOS, ABC (ASIEP). ${ }^{54}$ These had focused on distinguishing autistic children with low intelligence from children with other kinds of developmental delays, or from typical children. However, with the growing acceptance that 'autism' was a unique kind of sensory impairment that had its own internal mechanisms, and was not merely the antithesis of intelligence, led to new approaches.

The ADI and the Autism Diagnostic Observation Schedule (ADOS) drew from techniques employed by British sociological researchers and indeed the widespread sociological studies that Rutter had conducted in the 1960s and 1970s. The ADI was designed to numerically code behavioural descriptions, rather than to numerically code 'yes' or 'no' answers. The creation of a questionnaire that did not seek any 'yes' or 'no' answers could be traced right back to the Isle of Wight study, which constantly sought clarification in the interview technique in order to 
recreate the closest thing to actual observation as possible. In fact, this was a skill being developed by the new generation of British sociologists in the 1960s as well, to get as close as possible to the representation of reality through the use of interview techniques. It took much time and many resources but sociologists argued that it generated true snapshots of society, true images of the life of large groups. Interviewers had to be trained to encourage their informant to remember real events and to report these accurately so that the 'behaviour' was recaptured without the need for direct observation. When creating the ADI, Rutter and colleagues argued that creating a snapshot was more reliable as a diagnostic tool because it got closer to presenting the behaviour that a clinician may observe in practice. Furthermore, the ADI employed creative psychological techniques, such as reference to birthdays, family holidays, Christmas or other key events, in order to gain the correct age range from parents who were recalling earlier developmental stages. Family events would then be cross-referenced in order to ensure the reliability of reported behaviour. This method of measurement enabled the interviewer to collect, analyse and measure multiple 'scaled' behaviours in a way that was impossible with most rating schedules. The ADI was thus the pièce de résistance of developmental interviews that enabled such a detailed exploration into a child's development and behaviour that it was almost impossible to criticise its precision. Interviewers used parental recall to recreate an individual child's entire development. The form covered 101 pages, each probing into the life of the individual child.

The first publication of the ADI in 1987 began with the collection of general family information, such as number of children and any known health problems in family members, followed by a detailed summary of education and contact with special educational services. The parent or carer was then asked what were his/her main worries and concerns about the child and what symptoms they had noticed, at what age, and whether previous medical advice had been sought. Specific information was taken about developmental milestones such as when the child first walked and sat unaided. The interview then covered different aspects of the child's development starting with their language development and other methods of communication, and then explored 'social development', covering similar territory to the Gesell scales such as whether the child held a direct gaze, smiled or anticipated gestures and at what 
age they started to do this. ${ }^{55}$ The next section moved on to 'social intentionality', such as when the child tried to get attention and whether they could discriminate between adults. 'Imaginative play' explored the child's play with toys and the nature of that play, such as whether toys were used as whole objects or parts, and whether they were used as part of wider 'pretend play'. After early development had been ascertained, the interviewer focused on the child's behaviour in the last year, focusing on language in detail and exploring the child's use of metaphorical language, for example, as well as their articulation and vocal expression. The parent or carer was then asked about the child's responses to other people's feelings, and whether they had friends their own age. They were questioned even further about the child's recent imaginative or creative' activity, and then asked about whether they had any 'unusual preoccupations', 'compulsions' or 'rituals', or any abnormal responses to sensory stimuli. Finally, the interview turned to whether there were food fads, pica, overactivity, underactivity, stereotyped movement, tics, vocal tics, unusual gait, self-injury or loss of skills. ${ }^{56}$

This ultimate overview of every aspect of a child's development was not just a means for identifying a set of behaviours as in Lotter's model, or even a means to identify impairments and handicaps as in Wing and Gould's HBS Schedule, it was more of a means to observe social behaviour in childhood in all its complexity. It was as if Rutter was arguing that if DSM-III-R was expanding the category, then it must now take all of childhood social development into its observational remit. Rutter then made it very clear that Wing's 'style of reasoning' about autism was associated with a wider change in how social development in children was perceived.

Just in case informants were not reliable, the ADI was supported by the ADOS. Again, this was another way to create a snapshot of the child using the logic of sociological research, designed to recreate social situations as accurately as possible, without the child being aware that this was what was happening. It was also another example of psychologists creating the environments and social settings in which to house their newly formulated concept of autism. As it was described in 1989:

The general format of the schedule is to encourage an interaction that appears natural, during which preplanned 'occasions' for certain behaviors arise, with the imposed structure as invisible to the subject as possible. 
However, in reality, this structure has been carefully determined in terms of social tasks that are defined in detail by variations in cognitive demands, in the type of materials, and in the behavior of the interviewer. These standard situations thus provide comparable social stimuli for all subjects. ${ }^{57}$

This set-up fused clinical observation with experimental psychology where 'the examiner is considered a participant/observer or confederate in a social experiment', thereby multiplying the points at which psychologists could observe and record children's behaviour. These were no longer limited to the institutional settings of clinics, nurseries and schools, but now encompassed the newly created faux social environments of the ADOS, as well as multiple sites of memory that were gleaned through the $\mathrm{ADI}$ interview setting. It was via these multiple points of observation that the autism category would find increasing support for its validity and rationality. The consistency, frequency and abundance of these observational settings meant that the new meaning of autism was frequently reinforced and supported. There was no way that a theory of psychology grounded on unconscious instincts could compete with this new-found quantifiable, calculable and computable evidence for 'social impairment'. It was very hard to present any kind of argument about 'autism' that researchers could not systematically debunk, or at least fend off, using knowledge collected from the ADI and ADOS. The ADOS was also videotaped, therefore increasing its potential as a self-reinforcing instrument. The more that social situations were acted out, the more those particular interactions could be observed, memorised and re-enacted by future assessors. At the same time, the more that children were observed responding in a particular way in a 'social' scenario, or responding to mechanical objects in particular ways, the more this would be used as evidence that this behaviour was a variant of autistic behaviour. For example, training tapes for ADOS and ADI released in the early 1990s referred to a case of a boy with a strong interest in computers who was given a diagnosis of Asperger's syndrome. ${ }^{58}$ The increasing number of boys with an interest in computers in late 1980s and early 1990s was a cultural phenomenon, but the $\mathrm{ADI}$ and $\mathrm{ADOS}$ enabled the creation of scenarios in which such interests could be probed. It thus provided a framework in which a child's play with these objects could become a reason for a diagnosis. 
Although Lorna Wing had been critical in developing the description of the triad of impairments through epidemiological studies, she did not have the social scientific expertise that Rutter had developed through his prolific social surveys. This gave him the edge when it came to developing a complex diagnostic instrument based on interviewing techniques and working with international collaborators to formalise it. Wing's response was the creation of the Diagnostic Interview for Social and Communication Disorders (DISCO). Although it had a catchy acronym, it was an awkward testing instrument and never caught on in the same way that the ADI did. ${ }^{59}$ Hence the ADI and the ADOS became the 'gold standard' for autism testing. The building international consensus over testing instruments for autism enabled autism to become an important aspect of the growing 'statistical psyche' in which statistical and epidemiological instruments offered the promise of explaining and fully comprehending the mind. Just as intelligence was a measurable entity that could be applied across a total scale, so autism also became a similar measurable entity. The ADI and the ADOS helped to consolidate this entity and to expand its measurable dimensions.

The growth of testing instruments, such as the $\mathrm{ADI}$ and the ADOS, helped to popularise the idea that autism was part of a general scale of human development and that it was therefore a topic of interest to many people, not just the minority who were affected. As Stuart Murray has argued, in the 1980s and 1990s theories of autism were popularised through proliferating media channels that had international reach. ${ }^{60}$ The Hollywood movie, Rain Man (1988), spurred a series of articles on autism in the press that directly linked this film to current scientific theories of autism. Writing for New Scientist in 1989, John Morton argued that 'Rain Man has drawn the public's attention to this mysterious disorder', later clarifying what autism is: 'there is a cognitive deficit underlying autism which amounts to an inability to create certain kinds of representation, particularly of other people's mental states. ${ }^{61}$ In 1993, Uta Frith wrote an article for Scientific American that drew attention to Rain Man, whilst also popularising her work. She put her theories in a nutshell with formulations such as: 'The autistic child has a mind that is unlikely to develop self-consciousness. ${ }^{\text {' } 2}$ Ideas about autism were definitely reaching a wider audience, but at the same time they were also developing the potential to be abridged, simplified and somewhat altered in their meaning. Just as testing scales enabled the concept to be 
expanded as part of a wider model of statistical psychology, so did the representation of autism in the media. This led to new summaries and articulations about what, exactly, autism was, and ultimately led to shifts in the meaning of the concept. The work of the new autism researchers was fundamental in defining these new conceptions of autism.

In 1991, the British Psychological Society issued a media release about the work of Frith at the MRC Unit and the light it shed on all people with unusual interests including 'academics' and 'collectors. ${ }^{6} 3$ Frith would later speak to the press about trainspotters, walking encyclopaedias and trivia collectors. The autistic children of the 1960s had now grown up and such unusual adult behaviour was now a topic for psychological scrutiny. 'Train spotters "may suffer from autism", declared a headline in the Independent. 'Train spotting is fertile ground for people with Asperger's syndrome', Frith argued, and went on, 'not all train spotters have this syndrome, but I know one, for example, who is really interested in carriage light fittings. That is fairly specialist. ${ }^{64} \mathrm{By}$ the mid-1990s, autism was established as a topic of general journalism and this was encouraged by the publication of several literary works by individuals who had been diagnosed with autism as children such as Birger Sellin and Donna Williams. ${ }^{65}$ Furthermore, television programmes helped to exhibit the preoccupations and talents of people who had received the autism diagnosis. In 1987, the BBC documentary, The Foolish Wise Ones, featured Stephen Wiltshire, a boy from South London with an extraordinary talent for drawing. In addition, more popular books emerged on the subject such as Oliver Sacks' An Anthropologist on Mars (1995), which also featured Stephen Wiltshire as one of the cases. Wiltshire has since received an MBE for services to the art world and is now an internationally renowned artist. ${ }^{66}$ An article in the Guardian in 1995 described all these popular representations of autism, arguing that although the Institute of Psychiatry trained scientists appeared to have agreed on a definition, there was much work to do. As the journalist put it, rather wryly, 'After half a century of seeking an answer, the world's experts have barely worked out the question. ${ }^{67}$

There was something of a self-fulfilling prophecy here: just as measurement scales became increasingly definitive, the demarcation of autism was readily expanded through journalism and general discussion. 
Uta Frith's students, Simon Baron Cohen and Francesca Happé were the most passionate public writers on the new autism. Like Bowlby and Winnicott had done in the 1950s, they used available media formats in the 1980s and 1990s to ensure that the public understood the new science of autism sought to ensure that new theories of autism were popularised to a wider audience and that ideas about autism were clarified in the minds of the general public both in the UK and abroad. Simon Baron-Cohen and Patrick Bolton's Autism: The Facts (1993) sought to clarify new approaches to autism by Maudsley-trained psychiatrists and to support the view that 'modern medical evidence suggests clear biological causes for autism. ${ }^{68}$ Francesca Happés Autism: An Introduction to Psychological Theory (1994) stated confidently that 'Autism is not caused by refrigerator parenting'; 'Autism is not confined to childhood'; 'Autism is not always characterised by special or "savant" skills'; and 'Autism is not just a "shell" within which a "normal" child is waiting to get out.' Luckily, she also knew what the new autism was and argued that 'Autism is a biologically based disorder'; 'Autism is a developmental disorder which lasts throughout life'; 'Autism is found at all IQ levels, but is commonly accompanied by general learning difficulties (mental handicap)'; and 'Autism is a severe disorder of communication, socialisation and imagination. ${ }^{\prime} 9$ This was a passionate manifesto for the new autism, and it was incredibly persuasive. It helped to establish new 'styles of reasoning' about autism and social development that aimed to crush the Tavistock human relations model, and to establish a disability and rights-based model of autism.

\section{The big global increase}

The large rise in levels of autism across the globe began to be reported in the 1990s. This happened in line with the widespread adoption of Wing's model of an autism continuum or spectrum, as well as the growth in application of the $\mathrm{ADI}$ and $\mathrm{ADOS}$ in the process of diagnosis. These new concepts and tools were enabling a widespread statistically validated crushing criticism of the first autism and the creation of a new set of quantitative tools that promised to give meaning to the second autism in its new metamorphosis. As we saw in Chapter 5, these tools had been developed by a group of researchers in Britain who sought to 
challenge 'the Tavistock programme' and to provide new ways to think about psychological abnormalities within total populations. These new technologies were radically opposed to psychological models that did not integrate children with low intellectual levels. However, they were also radically opposed to hierarchical, planned social welfare models that imposed ideologies about the logic of care. The new autism was tailored to new liberal societies that sought to develop consumer-oriented models of care and to create models of child rights and disability rights that ensured these new models encompassed all members of society. By the early 1990s, everyone from children, parents, teachers and educational psychologists to lawyers, police officers and social workers had a clear set of criteria that could be used to make their own claims and inferences about child psychology and about the needs and rights of children.

By the mid-1990s, it became apparent that many more children were being diagnosed with autism in Britain than previously. Writing in the British Medical Journal in 1996, Wing summed this up as follows: 'Autism seems to be on the increase. This at least is the feeling of many professionals in the field of child development in Britain, who believe that in recent years they have been seeing more children with autistic spectrum disorders. ${ }^{70}$ Wing pointed out that it was not possible to compare pre-1979 epidemiological studies of autism with post-1979 studies, arguing correctly that her own epidemiological study in 1979 had linked autism to a 'range of developmental disorders' that had since become known as 'autistic spectrum disorders', thereby expanding the category from previous definitions. In 1996, Wing argued that there was 'no evidence for or against an increase in prevalence' of autism, espousing an ambivalent approach to the problem that was ultimately unsustainable. $^{71}$

Wing's ambivalence in 1996 is interesting given her significant role in championing the new model of autism. What is more, her promotion of the Asperger's category, which specifically included individuals with high intelligence levels, added new figures to the general field of autism epidemiology by adding an additional category to measure. In 1993, Gillberg and Stephan Ehlers published an epidemiological study based on diagnostic criteria for Asperger's taken from ICD 10 and also criteria devised by Gillberg himself that included 'Social impairment (extreme egocentricity)' with subcategories such as 'lack of appreciation of social 
cues' and 'lack of desire to interact with peers'. They found a prevalence rate of 0.71 per cent $(0.97$ per cent of all boys and 0.44 per cent of all girls), a figure that surpassed their expectations. Gillberg's study placed Asperger's well and truly on the map of population health epidemiology, ${ }^{72}$ whereas before his study, it had been viewed with some wariness and suspicion. The epidemiological engine that was driving the expansion of diagnoses was demonstrating that Asperger's definitely existed. Of course it did; it had an epidemiological study to back it up.

When DSM-IV was published in 1994 it retained the 'triad of impairments' for 'autistic disorder' but it also included 'Asperger's Disorder' as a distinct category and a subtype of what were termed, 'pervasive developmental disorders'. The criteria for Asperger's diagnosis were similar to those for 'autistic disorder' but Asperger's did not contain the 'qualitative impairments in communication' feature of the triad. In fact, the criteria specifically stated that in cases of Asperger's, 'there is no clinically significant general delay in language' and 'no clinically significant delay in cognitive development', thereby encouraging the diagnosis in children who only presented with 'qualitative impairment in social interaction' and 'restricted repetitive and stereotyped patterns of behaviour, interests or activities. ${ }^{73}$ If a child met only three behavioural criteria, such as 'failure to develop peer relationships appropriate to developmental level', 'lack of social or emotional reciprocity' and 'persistent preoccupation with parts of objects', then they would meet the criteria for an Asperger's diagnosis.

In Britain, many researchers with links to the Institute of Psychiatry began to challenge the category of Pervasive Developmental Disorder, in particular the prefix 'pervasive', which had emerged in DSM-III as a catch-all category that included autism. In 1991, Gillian Baird, Uta Frith, Lorna Wing, Simon Baron-Cohen, Christopher Gillberg, Patricia Howlin and others has written an open letter to Developmental Medicine and Child Neurology arguing that although it was a good thing that autism had been recognised as a developmental disorder, and thus associated with mental retardation and other developmental problems rather than emotional problems, this had been overshadowed by the fact that it was classed as a 'pervasive' developmental disorder. Clinicians increasingly challenged the contention that autism was pervasive at all as it was possible to have the condition in a minor form, yet the idea of a 'mild pervasive developmental disorder' was an oxymoron. In Britain, 
autism was regarded as anything but 'pervasive'. Gillberg later added that the 'Pervasive Developmental Disorder' diagnosis often meant that those diagnosed under the broader label, yet not classed as 'autistic', were not getting the help they would be legally entitled to were they classed 'autistic.' ${ }^{74}$ 'Pervasive Developmental Disorder' was the ultimate misnomer, yet it was a step on the way to creating a broader definition of autism. As it happened, DSM-IV quelled many of these concerns by adding Asperger's to the list, thereby making it very clear that Pervasive Developmental Disorders were not always 'pervasive'.

The addition of Asperger's and the debates over Pervasive Developmental Disorders led to many slippages and indiscretions in the language surrounding autism, the 'autistic spectrum', Asperger's and pervasive developmental disorders generally. Autism was increasingly associated with the concept of 'neurodevelopmental disorders' to the extent that 'neurodevelopmental disorder' became used often as a synonym for 'autistic spectrum disorder. ${ }^{75}$ At the same time, the term 'neurodevelopmental' was growing in its application to describe all childhood psychological disorders that were thought to have any kind of correlate in brain chemical development, including dyslexia, dysgraphia and 'clumsiness. ${ }^{76}$ Just as diagnoses of autism and autism-related conditions grew, the psychology of 'neurodevelopment', along with a wealth of neuroscientific studies, became focused on broad problems of social interaction and 'social impairment'. This burgeoning scientific field of genetic and neurochemical research into 'social impairment' supported Frith, Baron-Cohen and Leslie's 'Theory of Mind' hypothesis. ${ }^{77}$ It has also increasingly meant that attempts have been made to identify 'social phenotypes' within neurodevelopmental disorders both in Britain and internationally. ${ }^{78}$ Autism has served as a central concept through which to approach such studies.

International studies of autism began to thrive in the 1990s, with some pointing out that changing diagnoses seemed to be leading to more reported cases. Drawing directly from Gilberg's epidemiological approach, a 1996 study by $\mathrm{H}$. Honda on rates of autism in Japan, gave a rate of 21.1 per 10,000 using ICD 10 criteria. Half of that figure concerned 'high-functioning cases. Without attending to philosophical and scientific inconsistencies, Honda argued that this 'proves the existence of more high-functioning cases. ${ }^{79}$ An Icelandic study by Magnusson and Sæmundsen then showed very different rates for children classed under ICD 9 and ICD 10 criteria in the 1990s, and the authors conceded that changing diagnoses were definitely leading to increased cases. ${ }^{80}$ 
The increased awareness of more diagnoses only encouraged further epidemiological studies in the UK and abroad. In 1997, the British National Autistic Society founded the journal Autism, to 'encourage free dialogue between practitioners and researchers working throughout the world in autism. ${ }^{81}$ In the late 1990s, Uta Frith's student, Simon BaronCohen, along with Gillian Baird and others from both the Newcomen Centre at Guy's Hospital, London, and Cambridge University, used new testing methods to argue that there were, in fact, 57.9 per 10,000 children with 'autistic spectrum disorders', a term used increasingly to refer to almost all 'pervasive developmental disorders. ${ }^{82}$ After this figure was published, a flood of international studies confirmed that the rate for all 'autistic spectrums' was also very high. A study from the same year in New Jersey, USA, came up with a figure of 67.4 per 10,000 , a Danish study with 30 per 10,000 in 2002, a Cambridge study with 58.3 per 10,000 in 2002, and an Atlanta study with 34 per 10,000 in 2003. After the UK Department of Health admitted they were puzzled and concerned by the increase, being reported. Gillian Baird and others then looked back at the South Thames population in the UK and came up with an even higher figure of 116.1 per 10,000, also translatable as over 1 per cent of the total child population or 1 in every 64 children. Two US studies across states then came up with 66 per 10,000 and 67 per 10,000 respectively, with Denmark then coming in at 53.3 and Canada at 64.9 in 2006. The Australians and the Chinese were a little more cautious but came up with figures in the thirties and forties per 10,000 in the mid-2000s, but the British and North Americans continued to publish studies with around 60 per 10,000. In 2008, a Japanese study then went out on a limb with a rate of 181.1 per 10,000 , verging on 2 per cent. ${ }^{83}$

Autism has since been reported to have grown in such proportions that it has become common in popular literature to talk of an autism 'epidemic' ${ }^{84}$ This is somewhat ironic because Wing's autism, the second autism, is hugely dependent on the science of epidemiology to delimit and demarcate its boundaries. The initial reaction to these increased diagnoses was cautious, but it did not take long before multiple theories and explanations were put forward to explain this phenomenon and discussions of the autism epidemic took place on an international platform. Wing's expansion of the category, and the theory of the 'autistic spectrum', became an international phenomenon through 
DSM-III-R and ICD 10 which followed her definitions. This led eventually to reports of increases internationally. Wing's definition of 'autism', what one may term the 'total population definition of autism', was carried out in the interests of establishing comprehensive, inclusive epidemiological studies of child development. However, it then unleashed a spread of interpretations, analyses, qualifications, explanations and rationalisations internationally.

The first decade of the new millennium saw increased global reflection and consideration over whether or not this epidemic was 'real'. For example, Ashley Wazana and others from Columbia University in 2007 asked whether 'the autism epidemic' was a 'fact or artifact'. Helen Leonard and others from the University of Western Australia spent much of the 2000s 'unpacking the complex nature of the autism epidemic'. Jørn Isaksen and other Norwegian researchers simply asked: 'Autism Spectrum Disorders: Are They Really Epidemic?' 85 They were aware that there had been changes in diagnostic criteria and diagnostic practices, that the promise of additional school help encouraged parents to get a diagnosis for their child. They also knew that there had been an increase in the number of professionals able to identify autism, as well as their ability to reach younger age groups. However, none of this explained why the world had become so focused on 'autism' and ASDs in particular, as opposed to any other disorder, and why health and education institutions were so keen on working with, and thinking about, this particular 'triad of impairments'.

This seemed to be a puzzle for many who oversaw the increase. As Gil Eyal and Eric Fombonne have argued, these higher rates were in large part a reflection of the fact that children with both higher intelligence and lower intelligence, or retardation, were also included in the studies. ${ }^{86}$ Simon Baron-Cohen's development of the Checklist for Autism in Toddlers (CHAT) has also encouraged earlier diagnosis, serving a pre-emptive purpose. The ADOS has improved the techniques used to measure autism accurately, which is in many ways self-fulfilling. The more the ADOS is used in studies and confirms findings, the more it is recognised as an accurate measure of autism, and the more it is used in future studies. As described throughout this book, changes in the institutionalisation, schooling and treatment of children who show atypical development have also helped to increase the observation of autism. Similar changes have occurred in the USA and many other countries. 
Since the increased attention focused on the autism 'epidemic', other countries across the world have begun to wonder about rates of autism and whether these have changed. Needless to say, researchers from these countries look straight to the DSM, the ICD and to testing instruments such as the ADI and the ADOS, rather than to Bleuler, Piaget or others who described autistic thought before the onset of epidemiologically defined autism.

Controversies surrounding the autism 'epidemic' have built up an awareness of autism and provided fertile ground for further research. News and reports of an autism epidemic have definitely placed autism firmly on the international health research agenda. This has forced other countries to rethink their theories of intelligence and child development and has challenged them to embrace autism as a charity cause and to do more research into the issue of autism and social impairment. All of this activity supports the spread of the second autism within a wider theory of psychology, creating a solid body of research activity built on this model. There is now a global tendency to think of child development in terms of autism and the autistic spectrum and so epidemiological studies for this purpose flourish all over the globe. And although many people have asked questions about the increase, no one has asked why this particular model is so attractive to child psychologists and others. The answer, however, is more obvious than it seems. Wing, Gould and other Maudsley-trained psychiatrists developed a way to calculate 'social impairment' across entire societies. They devised a way to measure the limitations of this entity called 'society' via the study of some of its most vulnerable members. The 'triad of impairments' was a powerful organising concept that came to replace intelligence as a way to measure the limits and potential of advanced social organisation. A 'society' is only as good as its ability to detect and assist all its members who are 'socially impaired'.

\section{Hope is not a dream}

As increasing numbers of epidemiological studies were conducted, developing countries sought to emulate European and American research into autism as it was regarded as a reflection of improved children's rights and disability rights. This was accompanied by a growing 
number of international conferences. In the early 1990s, international conferences on autism focused almost exclusively on successful treatment methods. In contrast with the overall despondent and hopeless attitude to the first autism, the attitude towards the cure of the second autism was hugely optimistic and encouraging. In 1996, the Autism Europe Conference was held in Barcelona with the title: 'Hope Is Not a Dream'. A 1993 International Conference on Autism held in Ontario had only twelve papers on biomedical research out of a total of seventy, with the majority focusing on approaches to develop language and communication skills. ${ }^{87}$ The year 1994 saw a variety of new, sometimes controversial, treatments for autism publicised. A 1994 international conference organised by the National Autistic Society, bringing together researchers from twenty-three countries, showcased 'facilitated communication', which involved physical support and touch to encourage communication by Richard Brooks at the Chinnor Resource Centre in Oxford, UK; 'The use of video techniques' to develop language skills by Fahri Zinhi in the UK; 'Auditory integration training' by Aditi Silverstein from Innovative Therapies, Roanoke, USA; the Storm House Positive Approach by Kit Howe and Geoff Evans from the Storm House School in Rotherham, UK; the gluten- and casein-free diet by researchers at the University of Oslo, Norway; and the use of computers in teaching people with autism by Stuart Powell from the University of Hertfordshire, UK..$^{88}$

There was a huge amount of optimism concerning the treatment of autism in the 1990s amongst some biomedical and educational professionals. This is another cause of the skyrocketing of diagnoses. Even more importantly, the assurance of welfare rights to all those diagnosed ensured that the diagnosis was extremely popular. The European parliament adopted an abridged version of Autism Europe's charter of rights as a written declaration on 9 May 1996. The European Commission's Communication on Equality of Opportunity for People with Disabilities (1996) argued for a 'renewed impetus towards the rights-based equal opportunities approach to disability'. The Council Resolution on Equality of Opportunity for People with Disabilities (1996) reaffirmed that people with disabilities should have 'equal opportunities for productive employment in the labour market. ${ }^{89}$ In 1997, Rita Jordan from the University of Birmingham, UK, wrote a guide on the 'Education of Children and Young People with Autism' as the tenth in a series of 
UNESCO 'Guides for Special Needs Education' This all ensured that Wing's triad of impairments was recognised in changing education and employment legislation across Europe.

In 1998, Pat Matthews, director of the Irish Autistic Society, then established the WOA in collaboration with Autism Europe, with the aim of 'the protection and enhancement of the lives of children and adults worldwide'. They quickly arranged meetings with the WHO and UNESCO and established a bank account in Brussels to receive funds, in collaboration with Autism Europe.

In the same year that the WOA was established, Autism Europe published a Code of Good Practice on Prevention of Violence against Persons with Autism. ${ }^{90}$ This featured reports by several European specialists working with autistic people as doctors and carers. It reinforced the idea that autistic people had human rights that were similar to, but distinct from, those of the rest of the population. Donatta Vivanti, president of the Associazione Nazionale Genitori Soggetti Autistic in Italy, pointed out that 'parents may sometimes impose excessive social promiscuity' on a child with autism without realising that their inability to understand 'the complex rules that are implicit in our relationships' left them susceptible to suffering and humiliation and in some situations even violence and abuse. André Foubert, Director of Maison Spécialisé d'Accueil in France, warned against physical violence, negligence and lack of care in institutions, linking this with a wider movement to prevent violence against all people with mental disabilities. Bill Meldrum from the Scottish Society for Autistic Children argued that all 'organisations and public agencies working in the field of autism should have a code of good practice which takes account of the particular difficulties associated with autism. Christopher Williams from the Institute of Education, London, pointed out that omission, neglect and negligence could also lead to harm against autistic people. The Code of Good Practice also encompassed a scathing critique of psychoanalytic treatment for people with autism by Swedish self-advocate, Gunilla Gerland, which argued that the 'theory of object relations' and the use of transference and counter-transference models were useless in the treatment of autism because of 'the profoundly different way in which autistic clients interact'. She urged others to recognise that autism was a disability, that autistic people needed a 'positive disability identity' and that therapy could only ever treat the 'secondary symptoms' of autism 
rather than autism itself. ${ }^{91}$ They recommended to national legislators that 'Autism should be recognised in the legislation as a specific disability with specific needs and appropriate and sufficient services should be implemented to meet the needs of all people with autism including early diagnosis programmes. ${ }^{92}$ Thereafter, all national legislators should ensure that procedures were put in place specifically to prevent violence and abusive behaviour towards these individuals. At a European level, they argued that a Europe-wide constituency should be arranged regarding the guardianship, legal capacity and criminal responsibility of autistic people and that the European Commission should extend anti-discrimination and racial harassment laws to those with disabilities including autism.

Although the classification and diagnosis of autism was becoming more standardised by the late 1990s, there was still no clearly definable object called autism, and thus legal changes aimed at 'autistic' people had the potential also to define the rights of individuals who were as yet to obtain this label. The mid- to late 1990s also saw increasing reports that the diagnosis of autism could be applied to wider groups of children and adults as part of a spectrum, and led to questions being raised about the 'autism epidemic'. There is, of course, an irony to this situation because just as national and international law began to isolate and clarify the rights of people with autism, the number of people with autism began to increase. Laws concerning autism as a kind of social disability therefore applied to increasing numbers of people and affirmed their international rights to be non-social or non-interactive beings if they so chose.

Without any clear-cut biochemical basis for the category of autism, what essentially occurred from the 1980s in the UK, and from the 1990s across Europe, was that autism rights activists demanded that social institutions adapted their approach to social care and education based on Wing's model of the triad of impairments. Educational and social work institutions were urged, and later required by legislation, to alter their established practices of social betterment and social organisation based on the fact that there were some people who were impaired in their ability to act typically according to the demands of others. Instead of excluding those individuals according to ideal blueprints of social interaction, the post-1980s and post-1990s models of societal health and welfare ostensibly urged the inclusion of 'autistic' 
beings by marking out and legislating for their supposed social impairments. Such a model has been successful to a large degree, although its limitations obviously rest on the conceptual margins of the diagnosis and the fact that social institutions do not always easily alter their ideological assumptions about child development and socialisation.

The autism rights movement has increasingly demanded that all institutions, even including employers who previously had no approach to autism, alter their behaviour. In 1992, Autism Europe published a book 'describing autism', which was specifically to be used not for the purposes of researchers, in the vein of DSM and ICD, but rather as a way to work on a definition 'to establish the lifelong needs and requirements of people with autism'. It highlighted parental rights to be involved in treatment, but in its description it drew, again, almost wholesale from Wing. This distinction is important as it shows that Wing's definition of autism entered several different arenas. Within the global expansion taking place in relation to disability rights, Wing's autism was used to argue that individual rights and social, welfare and education services should be aimed specifically at protecting the 'dignity, individuality and capability of the person with autism' by providing opportunities for 'education, vocational training, and job opportunities. ${ }^{\prime 3}$ This is why it was so important.

The 1997 Amsterdam Treaty on Fundamental Rights and Nondiscrimination contained an article providing for action to 'combat discrimination' based on disabilities and also included a declaration to take into account people with disabilities in relation to single market harmonisation. This was a perfect opportunity for campaigners to articulate and clarify the condition of autism and the unique needs of autistic individuals and their families. For example, a message from Autism Europe addressed to European Commissioner Pádraig Flynn in 1997 urged that the employability of mothers of children with autism and others be enhanced by the creation of European policies encouraging flexible working hours within companies, so that these mothers are able also to care for their children in places where adequate education and support are lacking. Whilst supporting more freedom of movement in employment throughout Europe, they pointed out that parents, particularly mothers, of children with autism had a very limited level of mobility and thus whilst it was 'advisable to favour the free circulation of workers', this 'should not be done at the expense of the 
social values that are the basis of European society, i.e. the family'. They thus encouraged greater employment support for the families of disabled people and the integration of children with autism into European mainstream schools. ${ }^{94}$ Such an approach had clear political objectives to ensure that autistic people actually had a place in the new European and international model of the free market, rather than merely being placated without there being any real political will to enable those with 'social impairments' to integrate. In practice, in 1998, the Governmental Committee of the European Social Charter of the Council of Europe included Autism Europe in a list of international NGOs who were entitled to make collective complaints for violation of the European Social Charter, which is how autism began to be acknowledged in international law.

In the late 1990s and early 2000s, Autism Europe became increasingly globally focused. As part of the efforts of Autism Europe, Dr Joaquin Fuentes from the Child and Adolescent Psychiatry Unit, Policlinica Gipuzkoa, and Scientific Advisor of GAUTENA Autism Society, Spain, gave seminars to parents and professionals in New Delhi, India. Dr Hans Wulffsberg from the Danish Disability Council, and father of a son with autism, commented at an Autism Europe meeting that his work in Africa and Asia had led him to believe that 'the situation of people with autism in developing countries is dreadful as in most of these countries autism is not recognised'. He thus was keen to support a 2000 congress on 'Autism: Developing Programmes in Countries Where Services are Less Developed. ${ }^{95}$ This was part of a growing movement championing the rights of people with disabilities, supported by organisations such as the European Disability Forum (founded in 1996) to defend the interests of people with disabilities. Such changes have encouraged the developmental condition of autism to be conceptualised as a disability in order to encourage international action.

In 1999, members of Autism South Africa managed to get an article published in the Reader's Digest on the 'enigma' of autism that is 'incurable, but treatable'. In the same year, Isabel Bayonas, vice president of World Autism Organisation (WAO), organised a seminar on autism for Latin American countries in Columbia with parents and professionals attending from Brazil, Costa Rica, Cuba, Chile, Ecuador, Honduras, the Dominican Republic and Uruguay. Bayonas also helped to establish the Latin American Autism Federation in 1999, 
with Rosa Corzo from the Mexican Parent Organisation SOMAC as president. In the late 1990s, Autism Europe also made connections with the International Association of Child and Adolescent Psychiatry and Allied Professions (IACAPAP) in order to encourage further co-operation in autism research. ${ }^{96}$ Autistic societies across the world were also particularly savvy in using new Internet technologies, with the UK society founding an Internet-based conference in the late 1990 s and the WAO setting up their own website in the same year. In 2000, a workshop was organised for UNESCO in Glasgow, Scotland, which focused almost entirely on Wing's description of autism in its conceptual presentations. ${ }^{97}$ The fact that this has now become a global mission has helped to establish an Anglocentric approach to atypical child development in children generally through the spread of Wing's autistic spectrum.

Increased international debate also encouraged the exchange of ideas concerning the education and treatment of autistic children. In 1991 and 1995, the British National Autistic Society organised visits to the Boston Higashi School, a branch of Japanese treatment centres for autism established in 1987 that was very popular amongst parents. Judith Gould and members of the National Autistic Society wrote reports on the teaching methods used there. ${ }^{98}$ The school became known for employing the principle of 'Daily Life Therapy' aimed at encouraging children to dress, feed and clothe themselves and live independently, whilst also engaging in extensive physical exercise and using many techniques to stimulate each child's intellect. The aim was to prepare each child for mainstream education within 2-3 years at the school. The NAS 1991 report drew attention to the emphasis placed on physical education at the school, arguing that British schools could perhaps learn from this. The 1995 report also discussed the ways in which play therapy was employed in the school with a focus on 'the reduction of stereotypes and encouraging children to engage in what would be described as socially acceptable play', such as 'the bathing of the baby in the bath' or 'the running a car around a track'. Unlike the British technique of play therapy, these activities were not aimed at stimulating 'the imaginative development of the child' but rather on 'structure, predictability, routine and a clear and consistent rhythm to life. ${ }^{99}$ 
These techniques appeared to provide a means of encouraging a form of 'play' in autistic children, without the baggage of European models of play therapy that had become so closely associated with psychoanalysis, hence the popularity of these models amongst Western parents of children diagnosed with autism. In 1990, several parents in Britain appealed to have their children sent to the Higashi School in Boston at the expense of the local authority, though these appeals were unsuccessful. ${ }^{100}$ In 1990, the International Autistic Research Organisation was founded, reporting on international ventures and collaborations. This enabled the international promotion of various treatment programmes, such as the TEACCH programme that had been developed by Eric Schopler at the University of North Carolina in the 1960s after a general disillusionment with psychoanalytic models of therapy for autistic children. ${ }^{101}$ It claimed to iron out inconsistencies in applying professional approaches from separate disciplines such as speech therapy, occupational therapy, etc. and creating a unified model. The concept of autism had enabled a huge variety of innovative teaching methods, together with a flood of acronyms to describe them. These acronyms and fixed methods also helped to encourage international dialogue and were presented as products that could be assessed and purchased in an international marketplace. In the UK, the NAS Earlybird project promoted the SPELL approach that encouraged Structure, Positive (approaches and expectations), Empathy, Low arousal and Links. Other methods included the Son Rise programme developed in the USA by Barry and Samahria Kaufman in 1983 and Framework for Communication, developed by Phil Christie and Elizabeth Newson in the UK. ${ }^{102}$ These enabled parents and any other health care, social work or educational assistants and professionals to develop clear methods and practices in the treatment of children, many of which could even be applied to preschool children. For example, in the mid-1990s, the London Early Autism project was established to encourage the enactment of social play at a young age. ${ }^{103}$ All of these approaches enabled new networks to form, many of which were supported by ever-increasing Internet technologies.

As Silverman has pointed out, parent organisations, such as Autism Speaks, have empowered parents to set their own research agendas by affirming their ownership of genetic data and other data that researchers are dependent on. The databases Autism Genetic Research Exchange (AGRE), Autism Tissue Program (ATP) and Autism Clinical Trials 
Network (ACTN) were founded by Autism Speaks to enable scientific research based on parent agendas. US parental organisations have since become driving forces in increasing global autism awareness. In particular, Autism Speaks helped to found World Autism Awareness Day on 2 April every year. World Autism Awareness Day was ratified by the United Nations in 2007 in order to raise international awareness that:

autism is a lifelong developmental disability that manifests itself during the first three years of life and results from a neurological disorder that affects the functioning of the brain, mostly affecting children in many countries irrespective of gender, race or socioeconomic status, and characterised by impairments in social interaction, problems with verbal and non-verbal communication and restricted, repetitive behaviour, interests and activities. ${ }^{104}$

This classification was drawn almost verbatim from Lorna Wing's triad, enhanced by the statement that the condition knew no national boundaries.

In 2008, the United Nations World Focus on Autism forum was held, bringing together members of the United Nations Diplomatic Corps, autism researchers, advocates and political representatives including Sarah Brown, wife of the then British prime minister, Gordon Brown, and Ban Soon-taek, wife of United Nations Secretary General Ban Ki-moon, who chaired the discussions. Suzanne Wright, co-founder of the charity Autism Speaks, stated that, 'Autism is a global health crisis that knows no borders', adding that 'it does not discriminate based on nationality, ethnicity or social status. ${ }^{\prime}{ }^{105}$ Other speakers drew attention to the importance of identifying and treating autism internationally. Autism Speaks has since initiated its 'Light It up Blue' campaign, which has published pictures of major architectural monuments, such as the Sydney Opera House in Australia, Nelson Mandela Bridge in South Africa, Christ the Redeemer statue in Brazil, the leaning tower of Pisa in Italy and the Macau Tower in China, bathed in blue light on World Autism Day in order to raise global awareness of autism. Epidemiological figures are often used to support the need for global recognition. There would clearly be less global recognition, and medical research funding, if figures were still at 4.5 per 10,000 in England. In 2015, Autism Speaks put the figure at seventy million people with autism across the globe. ${ }^{106}$ 


\section{Autism epidemiology as a symbol of child rights and disability rights}

Low rates for autism have now become synonymous with a lack of education about disability rights. This is why many non-Western researchers have sought to emulate epidemiological rates of autism produced in Western countries. For example, epidemiological studies of autism in China only began in the mid-1990s with a study in Fujian using DSMIII-R criteria, together with the Chinese Classification of Mental Disorders 2 (CCMD-2), finding a rate of 2.8 per 10,000. Studies in China throughout the 2000s found rates ranging from 2.9 to 13.9 per 10,000. The CCMD-3 was published in 2001 using similar criteria to DSM-IV (1994), featuring 'autism' and 'Asperger's' as two of the six pervasive developmental disorders in order to classify cases. This influenced new perspectives on the condition, as did growing international public awareness of autism. In 2011, Ning Li and colleagues from the Institute of Population Research at Peking University, China, found a rate of 2.38 per 10,000 , still well out of kilter with most other international reports of that time. They based their figures only on information that had been collected from the Second China National Survey Sample on Disability (2006), in which a sample population of 616,940 children with disabilities were identified. The type of their disability was assessed using classifications based on ISD 10. The authors put the low rate down to the fact that it was based only on children already thought to be 'disabled' and that the minutiae of detail needed to identify a case 'may not be fully captured by the ICD-10', and appealed for better distribution and availability of Rutter and Lord's ADOS to help improve awareness and to obtain a more accurate rate. ${ }^{107}$

Similar appeals have issued from other countries. In 2011, Muideen O. Bakare from the Child and Adolescent Unit, Federal Neuro-Psychiatric Hospital, Enugu State, Nigeria, and one of the most prolific writers on autism in Africa, pointed out that no one had studied autism epidemiology since Lotter in the late 1970s and appealed: 'There is a need for epidemiological studies in Africa to define the magnitude of the problem of ASD and the characteristics of children affected by ASD in this region. ${ }^{\text {'108 }}$ In 2012 he conducted his own study investigating autism within a sample of children with intellectual disability, arguing that a 
higher percentage of intellectually disabled children appeared to have autism compared to the 1970s. Bakare found that 11.4 per cent of children with intellectual disability also had autism in his Nigerian sample, whereas Lotter found that only 0.7 per cent of children with intellectual disability in his total African sample had 'autism'. This only encouraged further investigation and again repeated the 'need for large scale epidemiological studies of autism spectrum disorders among sub-Saharan African children. ${ }^{109}$ A recent study across the Arab world employed the CHAT to test for autistic spectrum disorders. The reasons given for this are very interesting. As Eldin et al. put it:

With the apparent rise in the prevalence of ASD and the growing need to screen large populations of children, the members of the Eastern Mediterranean Association of Child and Adolescent Psychiatry and Allied Professions (EMACAPAP) developed a study using the M-CHAT to screen children for autism in the Arab world. ${ }^{110}$

The 'apparent rise in the prevalence of ASD' was an encouragement to developing countries to develop measures for ASD and to find out how they fared on the international map of autism.

The use of internationally ratified diagnostic tools makes sense when making such comparisons, but it is important that all these international researchers are then employing classifications devised by Wing, Rutter, Frith and others in the unique cultural moment described in this book. This is the legacy of the psychology of autism spectrum-making. Researchers are no longer interested in intelligence and intelligence alone, they want to know how much 'autism' their nations encompass because it has become a symbol of advanced nations, of ethical altruistic approaches to all children. It is also a symbol of a new version of humanitarian commitment. Developing nations state that they will no longer hide their autistic populations, and medical research companies support this approach because it promises to bring new neuroscientific breakthroughs. This represents a new version of psychology in a postcolonial context. This replaces human relations theory and more stagnant versions of evolutionary theory, society and psychology that were prominent in earlier work, such as that of Cyril Burt. This new psychology of autism enables atypical children to have their own autonomy but only via this particular set of psychological schemes, systems and concepts framed around the idea of the autistic spectrum. 
China presents an example case where growing media attention and growing international consensus have encouraged and enabled the uptake of epidemiological methods developed in Britain. In 1993, Tian Huiping founded Beijing Stars and Rain, a non-governmental rehabilitation centre for children with autism in China, after her son was diagnosed with autism at the age of two. In 2007, an English-language documentary about the school, Children of the Stars, became a global success and was nominated for several awards. ${ }^{111}$ It led to increased media focus on the school and, of course, increased awareness of autism in China. The film presents autism as a major humanitarian crisis that requires the best international medical and educational efforts. It shows the approaches to autism taken when no resources or understanding are available, including the tragic depiction of one mother's daily ritual of tying her autistic son to a chair. Many mothers travel across China to seek help at the rehabilitation centre. The growing awareness that the film generated fueled more epidemiological studies. In 2013, Simon Baron-Cohen and colleagues reviewed all previous Chinese epidemiological studies of autism to find a rate of 11.8 per 10,000 individuals with autism and 26.6 per 10,000 with Autistic Spectrum Conditions (ASC). They argued there was 'a potential under-diagnosis and underdetection of ASC in mainland China, Hong Kong and Taiwan, and a need to adopt more advanced methods for research of ASC in these areas. ${ }^{\prime 12}$ In 2012, Chinese versions of the ADI-R and the ADOS were approved by the publisher, Western Psychological Services, thus providing the ideal instrument for such an analysis. These instruments provide support for the development of the concept of autistic spectrum disorders across the globe. This model of psychology is often presented as the basis for humanitarian approaches to psychological conditions in children.

In Brazil, similar developments have taken place. Between 2002 and 2009, Brazilian researchers published 93 articles and 140 theses and dissertations on the topic of autistic spectrum disorders. In 2007, the Brazilian Ministry of Health established a working group responsible for the care of people with autism, as part of the Brazilian Unified Health System, also signalling the importance attached to this disorder in the field of public health. The working group has since highlighted its commitment to scientific research to improve care. ${ }^{113}$ Researchers at the Institute of Biosciences, Universidade Estadual Paulista, Campus 
de São José do Rio Preto, and the Department of Genetics at the Federal University of Rio Grande do Sul have since contributed to neuroscientific theories of autism. ${ }^{114}$ In April 2010, the first national Brazilian Meeting for Autism Research was held, bringing together representatives from government departments and research centres. Writing on science and society, several of the participants concluded that 'ASD cannot be considered a rare disorder anymore and over a million Brazilians are likely to be affected.' ${ }^{115}$ They argued it was therefore a major public health problem. Researchers have also drawn attention to the problems that arise when there is not an effective infrastructure to support interventions to help people with the diagnosis of 'autistic spectrum disorders'. Writing in 2014, Paulyane Gomes and colleagues from the Department of Clinical Medicine at the Universidade José do Rosário Vellano argued that 'difficulties in access to health care services and adequate social support contribute to increased levels of stress for caregivers of children diagnosed with ASD'. ${ }^{16}$ Gomes encouraged the formation of educational establishments, health care networks and related institutions to provide social support for families of children who have autism. This approach involves the adoption of measures for autism of which the ADI and ADOS are becoming global standards.

A few autism epidemiological studies have been conducted in South Asia, for example in Sri Lanka. Even fewer have been conducted in India, using largely indigenous instruments. However, new work now seeks to translate English-language autism screening and diagnostic tools into Bengali and Hindi so that global models of autism epidemiology can become a reality there. ${ }^{117}$

In India, many researchers now talk of the 'unmet needs' of children with autism. In 2012, a team of researchers from Sangath Centre for Child Development in Goa argued that there was a need to develop 'packages of care' for autistic spectrum disorders and other developmental conditions that could be 'delivered through a collaboration between trained community health workers and parents. ${ }^{118}$ Others frequently argue for better education for parents, health workers and teachers about autism in children and ways to manage this. The fact that new approaches to child disability rights come in one particular package is because it was this package that was exported via the DSM, ICD and the ADOS.

In Africa, Bakare's work has encouraged deeper reflection on all child rights. This has drawn attention to the discourse of children's rights as 
defined in the 1990 United Nations Convention on the Rights of the Child and the 1991 African Charter. The African Charter on the Rights and Welfare of the Child (2001) helped to ensure that children have a right to health, education and special care. In 2003, Nigeria adopted the Child Right Act and Bakare used this law to appeal for more training for health care workers and the mobilisation of child psychiatrists, pedagogues, speech and language pathologists and special educators. Bakare also pointed out the "unmet needs of children with childhood autism and other developmental disorders in the present healthcare delivery system. Such unmet needs are, of course, made apparent via epidemiological studies of autism that present a population figure for children who demand these services under the auspices of their rights as a child. ${ }^{119}$

The model of these sciences that is being spread internationally is not that of 'human relations' psychology but that of the autistic spectrum and the model of social development and social impairment that was developed in Britain in the 1980s and early 1990s as a challenge to the Tavistock hegemony. This psychological approach is now influencing theories of child development, education and socialisation across the globe. This is part of a wider international movement to adopt DSMstyle psychiatry. Although such as model is often criticised by those who think that it is part of a global conspiracy by drugs companies to make more money by peddling unnecessary drugs for psychological disorders, this is a simplification of the facts. ${ }^{120}$ In the particular case of autism, it is less easy to take such an ironic view of the condition and its diagnosis at an international level, because it is so intimately tied up with humanitarian approaches to education and improvement in social attitudes to disability. The growth of global autism research was paralleled with growing rights for children with autism in the UK. These built even further on those established before the 1980s.

In the 1990s, there was a growth of legal cases in which the rights of autistic children were challenged and tested. In 2000, the House of Lords established that LEAs could be held liable if they did not meet their duty of care to provide education to children with special educational needs. ${ }^{121}$ This coincided with a landmark High Court ruling in Ireland concerning the handling of provision for an autistic child where a family was awarded $£ 255,000$ in damages because the child's needs were not met by the LEA. ${ }^{122}$ In the same year, a Department of 
Health report co-authored by Simon Baron-Cohen argued that 'greater emphasis should be placed on the autistic spectrum disorders generally in relevant undergraduate and postgraduate programmes', and this has indeed happened with the study of autism being at the heart of many psychology programmes in Britain. ${ }^{123}$ Furthermore, the report placed great emphasis on ensuring that local authorities spot cases of autistic spectrum disorders early to prevent the development of problems later in life, such as psychiatric disorder, 'social exclusion' or contact with the criminal justice system.

In 2001, a report funded by the Local Government Association argued that any professional staff who were 'likely to come into contact with children with ASD' should be 'adequately trained and updated.' and that 'provision for younger children should be available' and that LEAs should put in place the means to track children's progress through various educational and health provisions. ${ }^{124}$

The legal recognition of autism has come as a result of work by Institute of Psychiatry psychologists and the Society for Autistic Children, ensuring that the rights and needs of people with this diagnosis were respected. It was the changes in the 1990s that helped to push through landmark legal changes in the UK, namely the Autism Act 2009. In 2012, children diagnosed with autism became the largest subgroup of children registered with a statement of special educational need. ${ }^{125}$ From a political perspective, it is obviously a challenge for politicians and policy-makers to devise coherent policy to integrate those with 'social impairments' into society. The creation of legislation specific to autism has been the first real attempt to do so, and to ensure that the psychology of autism spectrum-making finds its place on the political map.

The promotion of new international attitudes to child rights and disability has generated a new internationally accepted model of intervention into atypical child development. For example, in 2013, Brian Reichow from the Yale Child Study Center argued that low-level health care workers should be trained in developing countries to provide 'psychosocial' interventions for 'low functioning' autistic children. Unlike the kind of psychological help that was provided by child guidance clinics in England from the 1930s to the 1970s, which provided support by adapting family circumstances and intervening to support a human relations model of psychology, Reichow and others argue for 
'the development of daily skills. Cognitive rehabilitation, training, and support (interventions that facilitates the relearning of lost or altered cognitive skills)' and 'parental training interventions (which teach parents how to provide therapy services for their child) had strong effects on developmental, behavioral, and family outcomes'. Such an approach has had support from Bakare in Nigeria and in other locations where professionals face many economic challenges in establishing effective networks of care and education for children with an autism diagnosis. ${ }^{126}$ The approach is also supported by the WHO's Mental Health Gap Action Programme, which provides guidance to developing countries on how to deal with autism and other developmental disorders. This has shifted international attention away from the first autism within general theories of child development, and towards the second autism. If children meet the criteria for 'autism' or 'pervasive developmental disorders' then the intervention recommendations are markedly different from those suggested if they do not. Focus is placed on implementing social interventions such as parental skills training and the notification of educational institutions, etc. rather than direct intervention into the management of human relations. ${ }^{127}$ The degree to which the model of the 'autistic spectrum' outweighs human relations psychology depends on the number of children considered to be autistic, or how much the category is applied to high-functioning cases.

Wing's model of 'the autistic spectrum' has brought new visions of society, social organisation and social care into developing countries. The fact that epidemiological studies find increased rates of autism, whilst genetic studies find increasing complexity to the disorder and pathogens are still little understood, only compound and support the idea of the autistic spectrum, and encourage further anxieties around what it is all about. The spirit of international collaboration is now called upon in order to clarify both epidemiological rates of autism and also the international rights of autistic individuals. For example, in 2012, a large team of researchers from countries across the world, namely Canada, the UK, India, South Korea, USA, South Africa, Mexico City, Venezuela, Brazil and China, came up with a prevalence rate of 62 per 10,000 for autism and other 'pervasive developmental disorders' internationally. They pooled data from various locations across the Americas and the Caribbean, Western Pacific, Europe, Eastern Mediterranean and Southeast Asia. By providing a global estimate, 
these researchers did what Lotter had done for the UK in 1966: they drew attention to the lack of services for children and adults who could be classed with this condition. They argued that 'The need for services especially in low and middle-income countries is felt more than before. It is imperative to engage community resources and more peripheral extensions of health systems as well. ${ }^{128}$ Whilst developing countries had focused on infant mortality and basic diseases of childhood until the early 2000s, the growing focus on autism as a global health crisis has encouraged international organisations to shift their attention to child mental health too, an initiative supported by the WHO.

Whilst some researchers have drawn attention to the difficulties of such an approach in countries where resources are scarce, this does not detract from the ultimate message of autism evangelism, which is to start people thinking about atypical child development in terms of autism and about how these models can be harvested to construct a new model of children's rights and disability rights. ${ }^{129}$ It should therefore not be surprising that by the early twenty-first century, researchers from around the world were all in agreement in their description of the autistic spectrum drawing directly from Lorna Wing and DSMIV. Researchers from Egypt, Saudi Arabia, Oman, Kuwait, Syria, Tunisia, India, Nigeria, China and Brazil, to name just a few, all know autism, a central concept of child development, according to its new reincarnation. ${ }^{130}$

\section{Global anxiety and explanations for the increase}

Although descriptions of child psychological development and autism have become less focused on the imagination since the 1980s, the public imagination about the meaning and causes of autism has grown substantially. Britain has always been at the forefront of autism epidemiology but it has also always been incredibly reserved about making interpretations over reported increases. The one notorious exception to this reserved attitude is the work of Andrew Wakefield, who originated the vaccine hypothesis to explain increased rates of autism. Wakefield's work was particularly controversial because it threatened so many beliefs and assumptions about mental development and created a cultural crisis. Remarkably, Wakefield's theory then became the 
most widely circulated theory concerning environmental causes for the increase in autism cases.

In 1998, Wakefield, a gastroenterologist by training, published a study on twelve children aged three to ten years who were referred to a paediatric gastroenterology unit at the Royal Free Hospital in London. The children were described as having a 'history of normal development followed by a loss of acquired skills, including language, together with diarrhoea and abdominal pain.' ${ }^{131}$ Most were given a diagnosis of 'autism' and were given various tests including ileocolonoscopy, biopsy sampling, lumbar puncture, magnetic resonance imaging, electroencephalography, barium follow-through radiography, as well as the collection of biochemical, haematological and immunological profiles a level of testing for which he was later widely criticised. Wakefield claimed that he had 'identified a chronic enterocolitis in children that may be related to neuropsychiatric dysfunction' and that in most of the cases 'the onset of symptoms was after measles, mumps and rubella vaccination. ${ }^{132} \mathrm{He}$ also raised the possibility that the introduction of the vaccine in the UK in 1988 may be responsible for a reported increase in cases.

A press conference was swiftly held at the Royal Free Hospital where Wakefield made a case for splitting the vaccine into its component parts. After the press conference, several British papers published the story as front-page news. ${ }^{133}$ Wakefield's research was immediately controversial, leading to growing discussions and debates globally. This, along with Wakefield's persistent claims of a link, not least in a paper to the US Congress in 2000, 'triggered a collapse of confidence in the UK's MMR vaccination programme', as the chief editor of the Lancet, Richard Horton, described it, leading to a partial retraction of the article in 2004. ${ }^{134}$ The Wakefield article presented a medical explanation for the 'autism epidemic' that no other study had done, hence its immediate notoriety and the global attention that it attracted. In 2000, the MRC established a committee that agreed that there was no evidence of a link between MMR and autism and that the MMR vaccination campaign in Britain should persist, hoping to quell public anxiety. However, the vaccine remained controversial, with Wakefield continuing to publish claims of a link, for example in Adverse Drug Reactions and Toxicological Reviews (2000) and the Journal of Molecular Psychiatry (2002). ${ }^{135}$ In 2001, press reports that the then British prime minister, Tony Blair, 
refused to say whether or not his baby son, Leo, had received the MMR vaccine fanned the flames of the controversy. ${ }^{136}$ Public anxiety was further fuelled in the UK by televised dramas such as Channel 5's Hear the Silence (2003) followed by a televised debate, MMR: The Debate, where the actors and producers debated alongside Andrew Wakefield himself. ${ }^{137}$

In response to this ever-increasing controversy, the General Medical Council conducted an investigation into the conduct of the research and the way it was reported, and in 2010 the Lancet article was retracted and Wakefield was also removed from the British Medical Register. The story might have ended there, but Wakefield then moved to Texas where he continues to defend his research and his claims of a causal link between autism and the MMR vaccine. In 2013, he issued a statement that defended his claims about the MMR vaccine, making reference to several legal rulings where parents had been awarded compensation following the administration of the MMR vaccine to their children in Italy and the USA. ${ }^{138} \mathrm{He}$ has now become associated with a wider antivaccination movement in the USA and internationally that investigates not only the MMR vaccine but also the use of mercury in vaccines, and, indeed, wider research in the impact of environmental factors to the causation of autism. ${ }^{139}$

Nevertheless, epidemiological evidence to support Wakefield's claim was never forthcoming, which is important given the links made in both scientific literature and the popular press about vaccines being the cause of the autism 'epidemic'. The misrepresentation of the autism 'epidemic' by high-profile international researchers, journalists, politicians, parents and celebrities has not helped to quell controversy or to clarify the multiple factors at work in producing 'autistic' children. Prominent Internet resources such as US journalist Dan Olmsted's Age of Autism: Daily Newspaper of the Autism Epidemic and books such as David Kirby's Evidence of Harm: Mercury in Vaccines and the Autism Epidemic (2005) present increased reported prevalence of autism at face value, and not as part of wider historical shifts in diagnosis and in the presentation of children's rights. ${ }^{140}$

Epidemiological and statistical 'styles of reasoning' have been employed countless times in order to test Wakefield's hypothesis and each time they fail to prove it. Most epidemiological studies show that rates of autism have been rising, despite stable MMR inoculations. 
A 1999 study of children in North East Thames, London, found that clinical cases of autistic spectrum disorder had been rising since 1979, but there had been no sharp increase after the introduction of the MMR jab in $1988 .{ }^{141}$ A 2001 study in the British Medical Journal used the UK General Practice Research Database (GPRD) to conduct a time-trend analysis to measure rates of children with clinical diagnoses of autism in relation to uptake of MMR. Whereas rates of autism in 2-5-year-olds increased from 8 per 10,000 to 29 per 10,000 from 1988 to 1993, the uptake of the MMR vaccine had been stable in the same birth cohorts. ${ }^{142}$ Another 2001 study in the Journal of the American Medical Association found a 373 per cent relative increase in rates of autism from 1980 to 1994 in California, but only a 14 per cent relative increase in the uptake of the MMR jab. ${ }^{143}$ A 2005 study by Rutter and Hideo Honda found an increased rate of autistic spectrum disorder in a district of Yokohama city, Japan, even after the MMR vaccine was no longer given to children. ${ }^{144}$ Fombonne pointed out that although autistic spectrum disorder had increased over his eleven-year study of the child population of Montreal, the administration of MMR vaccines had actually decreased. ${ }^{145}$ Similar epidemiological studies came up with similar results in relation to mercury and vaccines, claiming that no causal link could be made from epidemiological data. ${ }^{146}$

However, the fact that there was no other reported or known reason for the 'epidemic' did not exactly help matters. Whatever their overall validity, vaccine hypotheses did plug a gaping hole in scientific knowledge about this condition that everyone thought had been measured so precisely and accurately with a wealth of new measurement tools and scales. How could it be that no one actually knew why autism was increasing? In 2008, Lynn Waterhouse from the Global Studies Programs at the College of New Jersey argued that there was a 'lack of explanation for the sharply increasing prevalence of autism'. Epidemiological studies giving increased rates stimulated, indeed demanded, explanations. As Waterhouse put it, 'Whatever its causes, the increasing prevalence of autism/ASD has put pressure on the field of autism research to generate productive and predictive theories.' Indeed, this was the case. However, she also pointed out that new theories of autism being generated did not seem to be 'additive and progressive' but instead rather ad hoc. ${ }^{147}$ Given all the time and effort that had been put into standardising and understanding the category of autism, it seemed incongruous 
that no one could convincingly explain the 'epidemic'. Wakefield's work was so popular because it promised so much. It promised to fully explain the autism epidemic, thus it was particularly ironic that epidemiological sciences never supported his claims.

It is no wonder that the general public thought that they were being manipulated as they were told that there was an epidemic, yet it had no known cause. What the controversy surrounding the MMR vaccine did highlight was the fact that parents, advocates and others no longer trusted that epidemiological data should be the sole domain of scientific researchers. There was growing concern that the public was being lied to, particularly in the USA. In 2003, a group of largely parent-led organisations, including the Cure Autism Now Foundation and the Autism Society of America, issued a statement urging easier access to a large database on vaccine safety, the Vaccine Safety Datalink, managed by the US Centers for Disease Control to enable the voluntary reporting of health variables in different populations that can be correlated with the application of vaccines in those areas. They hoped to further democratise mass data on vaccinations and epidemiological interpretations. ${ }^{148}$ In 2002, Sandra and Max Desorgher, directors of the World Community Autism Program in South Africa, communicated with Melanie Landman at the British National Autistic Society about 'The Vaccine Issue, Humanity and Autism, a Common Causal Factor', combining personal experience with evidence taken from various scientific studies, arguing that no hypothesis should be silenced. ${ }^{149}$

In the scientific literature, other genetic and environmental explanations were later proposed to explain the increase, although they never achieved the notoriety of Wakefield's claims. These explanations ranged from some that were very specific and emanated from case studies, to those that were extremely unspecific and could have enlisted any variable in an attempt to explain causation. For example, from the specific domain of biochemical research came the claim that children classified with autistic spectrum disorder had a significantly higher chance of having mutant forms of a gene for a folate-related enzyme, 5-methylenetetrahydrofolate reductase, and that the increase could therefore be linked to an increase in pregnant women taking folate supplements and improved survival rates for infants with a genetic polymorphism. ${ }^{150}$ At the other end of the scale came the claim from a team linked to Michael Waldman that autism prevalence was associated with precipitation or, 
scientifically speaking, 'there is an environmental trigger for autism among genetically vulnerable children that is correlated with bad weather', possibly because bad weather encourages more time indoors watching television. ${ }^{151}$ Increased rates of autism are now explored in relation to things as diverse as children's proximity to motorways; maternal metabolic conditions; maternal infections; the effects of prenatal vitamins; and lack of oxygen at birth to name but a few. ${ }^{152}$ Increased rates of autism have thus become part of a wider project to think about atypicalities in child development and their prevalence more generally.

To claim that the 'autism epidemic' is a historical by-product is not to claim that there are no environmental factors that may be affecting the development of autistic spectrum disorders as they are currently defined. However, it does take the edge off any sensationalism and ensures that researchers remain aware that their approach represents only one style of thinking when it comes to the formation of human identity and its differences. Gil Eyal's work has been fundamental in exposing the ways in which diagnostic change has affected the phenomenon of the autism 'epidemic'. However, it is not just diagnostic change across time that matters, but also wider historical changes that have affected the very thing that researchers are purporting to look for. As Paul Shattuck has pointed out, in the USA, diagnoses of 'mental retardation' and 'learning disability' declined as diagnoses of both 'autism' and 'developmental delay' increased. ${ }^{153}$ However, no one has been interested in why there was an increase in 'developmental delay', whilst there was almost mass hysteria over the 'autism epidemic.' This is because the second autism has become emblematic of children's rights to a 'typical', or rather a statistically 'typical', development. That has become a fundamental right for reasons that are beyond the auspices of current scientific enquiry.

Parent groups have attempted to acquire the rights to autism epidemiology, and to ensure that research is conducted according to their interests, because they know that so much is invested in this research. The production of knowledge about autism is part of a new global project to understand child development. This new project also has the potential to reframe wider claims about cause and effect in the development of social abilities in children. In fact, one could argue that there have been so many controversies about the autism 'epidemic' precisely because it was a category that built itself on the idea that child psychology could be completely known through epidemiological research. 
The second autism is intimately tied up with the epidemiological method itself. It is important to appreciate this fact in order to prevent researchers chasing too far up blind alleys. In fact, if Susan Isaacs, Melanie Klein and other psychologists who espoused the first autism could be criticised for their focus on the impact of instincts on thought processes in infants, one could equally criticise researchers who have latched on to epidemiological figures without looking at the multiple factors involved in their production, assuming that the numbers speak for themselves and that there is no need to challenge their validity when searching for causal hypotheses. This is largely because the core components of autism have shifted from the study of internal hallucinations to the study of epidemiology itself. As this book has argued, there was a dramatic shift in the 'styles of reasoning' used to understand autism and this dramatic shift has affected the kinds of arguments about causation that could be made about it. Epidemiological sciences have come to replace 'reasoning in cases', or thinking about individual lives, and this has had a major impact on how autism, and child development generally, is understood across multiple fields of enquiry. There is nothing particularly remarkable about this; it relates to changes in the way we think about child development. Nevertheless, the incongruity of Wakefield's claims to explain an epidemic with no supporting epidemiological data should not be forgotten, as it typifies the way epidemiological 'styles of reasoning' can be distorted way beyond their limits of enquiry.

Finding the biochemical correlates of the second autism

Although biochemical approaches to autism, such as Wakefield's, are often framed in relation to epidemiological data, there has also been a tradition of biochemical research unrelated to epidemiology. Allan Horwitz, Professor of Sociology at Rutgers University, USA, as well as other historians, sociologists, social commentators and others, have argued that psychological conditions are unlike other health conditions in that they have been primarily defined by symptomatology rather than biochemical correlates. ${ }^{154}$ However, this has not stopped researchers from delving into the possible genetic, biochemical and neurological differences between humans that may push them towards a diagnosis, and this has particularly been the case with the 
major conditions treated by drugs such as chlorpromazine, lithium, the amphetamines, etc. ${ }^{155}$ However, unlike other mental conditions, the search for biochemical correlates for autism has been a particularly complex project associated with brain development in children generally, and the ways in which children's physical development mapped onto their abilities to sense and engage with the social world. Early neuroscientific research into autism and autistic spectrum disorders was therefore never dominated by a project to tally the effects of a drug with the underlying mental condition that this drug was supposed to alleviate. Furthermore, twin studies and genetic research during the 1980s and 1990s was constantly being overshadowed by the fact that criteria for autism were rapidly changing and that investigations and fears over the autism 'epidemic' were constantly growing. This meant that early attempts to identify a specific gene abnormality for 'autism' quickly turned into more broad attempts to identify minute genetic variations that may or may not have an impact on the creation of a wider autism 'phenotype' and that, in total, were investigations into variations in child development generally.

Throughout the 1970s and 1980s, Michael Rutter had held on to the possibility that autism would be identified as a classic Mendelian genetic disorder. In the late 1970s, Rutter together with Susan Folstein, a graduate of Weill-Cornell Medical College then based at the Institute of Psychiatry, conducted a study of autism in monozygotic and dizygotic twins. Based on 'blind' diagnoses made by Rutter, they argued that autism was far more common in monozygotic than dizygotic twins, and that monozygotic twins also shared more 'cognitive abnormalities'. Although this was later often hailed as the first ever 'genetic' study of autism, it did not in fact examine genetic material in a lab. Studying the behaviour of twins was not as solid a scientific approach and, in fact, ended up only further supporting a much wider and looser category of 'autism'. As Rutter and Folstein put it, 'autism is genetically linked with a broader range of cognitive disorders. ${ }^{156}$ This category of 'autism' was much closer to that of 'intelligence', in which there was a strong genetic basis, but in fact a very variable scale in which one could present with impairments.

As with intelligence, this wider category of autism was given support via genetic studies, even though these never provided definitive proof that the category itself was genetic. Proof of the genetics of 
autism offered stark scientific evidence to what was otherwise a rather problematic psychological concept. Just as pioneers in early psychology and intelligence testing, such as Cyril Burt, had cultivated genetic approaches to this psychological concept, pioneers in the new autism psychology, such as Rutter, cultivated genetic approaches to autism in order to buttress its scientific legitimacy. Developing a theory of autism as a genetic disorder gave further support to the concept of autism as a psychological organiser. This only strengthened the flood of new tools to test, perceive and conceptualise and, above all, to measure the milestones and indicators of child development in relation to autism. However, as with intelligence, genetic proof for autism had major political implications.

The 1980s saw further work that supported the idea of a broad autism 'phenotype' characterised by impairments in social function. Reports from Britain and the USA found that siblings of children with the autism diagnosis often shared similar 'cognitive abnormalities' and suggested that there was a milder variant of autism. ${ }^{157}$ In the late 1980s, Rutter began a further family genetic study of autism together with Patrick Bolton and others from the Maudsley's Institute of Psychiatry, which employed the standardised ADI. This genetic research supported Wing's argument that 'autism' was not an isolated category, confirming a biological basis to the theory of a spectrum of autistic disorders. Comparing children classed as autistic with those diagnosed with Down's syndrome, Rutter and Bolton found 'a raised familial loading for both autism and more broadly defined pervasive developmental disorders' in those with autism, thereby encouraging a broadening out of the category. They argued that:

these data provide compelling evidence for broadening the phenotypic definition beyond the criteria usually specified for autism and other forms of pervasive developmental disorder. They also show that the broader phenotype is characterized by language-related cognitive deficits, social impairments and stereotypic behaviours, but not mental retardation, per se. ${ }^{158}$

A further twin study by Rutter and colleagues took a much wider epidemiological sample of autistic twins, and employed the $\mathrm{ADI}$ and $\mathrm{ADOS}$ for the purposes of diagnosis, finding a concordance rate for autism of 60 per cent for monozygotic twins and 0 per cent for dizygotic twins, 
with 92 per cent of monozygotic twins and 10 per cent of dizygotic twins concordant for 'a broader spectrum of related cognitive and social abnormalities', arguing that autism was a 'strongly genetic disorder.' ${ }^{159}$ Genetic research initially supported broader epidemiological research and, hand in hand, the two went on to sustain the development of the 'autistic spectrum'.

The DSM-III-R encouraged research into the biochemical basis of autism, such as the work of Christopher Gillberg, then based at the Institute of Psychiatry who conducted work on the cerebral spinal fluid of children diagnosed with autism in the $1980 \mathrm{~s} .{ }^{160}$ Lorna Wing's broadening of the autistic spectrum drew support from this genetic research. The prospect of a genetic basis thus supported the autism concepts that were being formulated, even as those concepts began to expand and envelop other definitions.

The early 1990s saw a growth of family studies that supported the autism concept from across Europe and the USA. Rutter and his colleague Patrick Bolton started to conduct family studies in which they randomly selected 100 children diagnosed with autism and then followed up and tested their first-degree relatives for metabolic and chromosomal abnormalities. ${ }^{161}$

At any rate, the genetic research was buttressing the epidemiological research and the broader category of autism. These worked hand in hand to outweigh and challenge case-based thinking about autism and to develop new global research networks on autism genetics.

By the mid-1990s, biochemical research delivered some major findings in individuals diagnosed with autism. Rutter published his followup work on children with the autism diagnosis and its association with epilepsy and fragile X syndrome. ${ }^{162}$ In 1994, Gillberg recommended that doctors include tests for neurocutaneous disorders, CAT scans, investigation of chromosomal structures, EEGs, blood and urine tests, collection of cerebral/spinal fluid and tests for visual and auditory systems. ${ }^{163}$ This supported a biochemical basis to autism, even as the category was still expanding its remit. Even in the 1980s and 1990s, biochemical and particularly genetic research supported autism's hegemony, and supported a broadening out of the category to echo the epidemiologically defined autism that was expanding its global remit, challenging earlier models of child development and redefining children's rights. Genetic research thus became an important reinforcement to these new models 
of child development even though the dream of a unique gene for autism receded pretty quickly.

The mathematical, logical, scientific autism

The growth in interest in genetic studies, coupled with a growing global market for epidemiological studies, gave autism a new-found fame as well as a new authority by the late 1990 s. Autism researchers quickly became authorities on child development when, in fact, their field of study had previously been very limited. One important development that occurred in relation to this was that new autism researchers quickly had to step up and clarify more clearly what they meant by 'social impairment. Previously, this had largely been formulated as a deficit model of what autism is. However, by the 1990s, more questions were being raised over what features were present in autistic children and how these could be systematically summarised, without having to resort to advanced complicated tools of assessment such as the ADOS. What had happened was that the second autism, formulated through the logic of epidemiological studies in the 1960s as an absence of fantasy, imagination and hallucination, had been expanded and globalised to such a degree that its portrayal as mere absence or 'social impairment' became increasingly difficult to justify. Into this social absence, researchers began to explain the new abilities, new capacities, new skills that autistic individuals may have. It is, for example, no coincidence that the idea that autism is characterised by marked mathematical and scientific skills arose in the 1980s in line with the expansion of the Asperger's category and the growth of a new theory of human relations. It is also not a coincidence that this model arose in the midst of mass collections of global epidemiological data on an aspect of child development that otherwise had no meaning. The growth in scales to measure autism came to define the concept itself. Unlike the expansion of any other psychiatric disorders, the problem with autism had always been associated with its role as a central organising concept in wider theories of child development. Gaps in knowledge about this central concept were increasingly filled with knowledge produced from the instruments used to measure it.

Measurement instruments for autism continue to grow. A perfect example of how autism scientists have attempted to mimic and 
outshine the intelligence test is undoubtably the creation of Simon Baron Cohen's 'Autism Spectrum Quotient', also known as the AQ. Baron Cohen developed the AQ in 2001, as an challenge to the supremacy of the Intelligence Quotient (IQ) as a means to measure the sum of human psychology and its genetic basis. This instrument could also be used on adults and all 'high-functioning' individuals, including mathematicians and scientists who Baron-Cohen has consistently argued display 'high-functioning autism' to a higher degree than the normal population. The AQ could be self-administered, thus making it an easy and convenient way to spread awareness of the triad of impairments and the significance of autism as a way to explain psychological atypicalities that affect social interaction and socialisation. ${ }^{164}$ Furthermore, Frith and her students also continued to develop theories of the wider 'cognitive style' of autism. Based on her studies of sensori-motor tests and pattern detection in autistic children, Frith had argued that 'central coherence' was a normal cognitive tendency to focus attention on extracting general meaning and gist or gestalt from information. ${ }^{165}$ Frith and Happé then argued that the autistic inability to extract general information could be called 'weak central coherence', which referred to a focus on parts, details and particulars rather than wholes. It was a way of thinking that on its own could actually be beneficial, enabling people to focus on details without worrying about the general gestalt, hence why Baron-Cohen identified engineers, mathematicians and physicists as having autistic traits. ${ }^{166}$ All these hypotheses provide alternatives to intelligence in their explanation of variances in children's thought. They also provide alternatives to human relations psychology. BaronCohen and others have thus skilfully constructed a model of 'autism' that beautifully reflects the tools that they have been using to measure it. The high end of the 'autistic spectrum' is now regarded as a condition marked by mathematical skill, scientific ability and logical thinking. This was exactly what the new autism psychologists were always looking for: logic, skill, rigour, numbers, certainty, proof. Because autism was such an illusive concept, this gave greater scope for psychologists to build a model of it supported by the instruments used to measure it.

Genetic studies have supported this epidemiological statistical autism - the second autism. There has even been increased standardisation of the category in even younger children. ${ }^{167}$ As the sociologist Gregory Hollin has pointed out, the assessment of autism in younger 
children, and the potential to identify it prenatally, has become an increased focus of much recent research in Britain. ${ }^{168}$ Internationally, younger diagnosis is also becoming more common. A later revision of the ADI in 1994 reduced the number of questions and made it applicable to younger preschool children, and a revision of the ADOS in 2012 included a toddler module. These instruments have since been adopted in many international settings.

At the same time, there have been increasing attempts to delineate the broader 'phenotype' of autism, such as in Baron-Cohen's work on the 'cognitive phenotype' of Asperger's syndrome. ${ }^{169}$ Indeed, the more children that received the diagnosis, the harder it was to challenge the category, or to deny the broader phenotype of autism. Increasing numbers of studies described different psychological profiles in family members as part of a broader 'autism phenotype'. However, the boundaries needed to be defined if researchers in molecular genetics were going to find the genes for autism. Another compelling argument for some kind of genetic cause came from the fact that all epidemiological studies consistently found a higher percentage of male cases in their samples. ${ }^{170}$ When it came to the extended wider category of autistic spectrum disorders and Asperger's syndrome, the figures were often even higher, with Wing arguing that there were fifteen times as many boys with Asperger's as there were girls. ${ }^{171}$ This led Baron-Cohen to develop his theories of autism as caused by the 'extreme male brain' in the late 1990s, later studying the effects of testosterone on brain development in foetuses and young infants to explore why male and female brains developed differently. ${ }^{172}$ One of Baron-Cohen's most formidable experiments involved the accessing of a bank of frozen amniocentesis specimens to measure foetal testosterone levels then later testing the babies in their psychological performances. They first measured frequency of eye contact with the mother as opposed to mobile and mechanical objects, then later language abilities, finding a correlation between high testosterone levels and low eye contact with the mother and restricted language skills. ${ }^{173}$ This finding supported various theories put forward since the late 1950 s relating language and cognition skills to sex differences. ${ }^{174}$ It also added to a growing number of studies examining the effects of testosterone on foetal brain development in both humans and rats following the work of Geschwind and Galaburda. ${ }^{175}$ In fact, BaronCohen's work on autism and the extreme male brain uses the concept 
of autism to understand gender differences in infants and children in very similar ways to the use of the concept by earlier writers, such as Anthony and Winnicott, to understand infantile unconscious drives for human relations; however, instead of trying to theorise the sex instinct within individual child cases, Baron-Cohen theorises the wider concept of gender across child populations. Baron-Cohen's work on autism attempts to explain an issue concerning sex differences and the impact of hormones on the function of psychological drives towards particular objects. It is another perfect example of how the study of autism led to a shift in psychology from a focus on instincts, unconscious phantasy and individuality to a focus on gender, behaviour and populations. This was not due to a greater understanding of autism as an aspect of the human condition. It was an artefact of the systems used to measure it.

For the new autism psychologists, what was being hypothesised in the biological realm was not desires, drives and motivations, but cognitive tracking devices that made individuals want to be social. The new generation of autism psychologists started to tie themselves to a theory of sociality as the innate capacity to mind-read, to detect patterns, to observe cues, to understand configurations and to map the thought of others. This was the new, epidemiologically defined, autism that would become a dominant model for thinking about child thought by the 1990s, the dominant 'style of reasoning' around child development. Statistics could now show the movements and compulsions of unconscious thought driven by instinctual and hormonal forces. It could reveal the depths of human drives and explain them without having to resort to conscious thought and description. It could explain instincts as a sum of statistical measures and so longer needed to rely on the logic of phantasy and drives.

\section{Molecular genetics and the success of the 'autistic spectrum'}

At the turn of the twenty-first century, many researchers thought that the genes for autism might be quickly discovered due to major advances following the establishment of the Human Genome Project by the US government. This stimulated genetic research into various conditions and also assisted the development of sophisticated tools to analyse genetic data. It became evident early on that no single gene mutation could be linked to autism and the focus shifted to full-genome scans coupled with candidate gene studies. Research into the genetics of 
autism has since helped to buttress the idea of a broad autism spectrum with complex genetic correlates.

Genetic studies of autism have increased rapidly since the late 1990s and have enabled a new international scientific community to develop. As several sociologists of autism have pointed out, autism research has come to attract large amounts of funding due to the popular status of the diagnosis. Much of this funding has been pumped into genetic research, particularly that focusing on 'susceptibility genes', as well as brain-imaging studies, because many companies have a vested interest in finding autism susceptibility genes and in demonstrating brain atypicalities that could potentially be rectified using pharmaceutical products. ${ }^{176}$ At the same time, the fact that autism researchers sought to compete with intelligence researchers prepared the ground for this focus on genetic research to flourish.

In 1997, early molecular genetic studies of autism looked to the 'serotonin transporter' (5-HTT) to find some biological basis to the disorder, serotonin having sprung to fame in the description and treatment of depressive disorders. These studies were conducted in the USA and Germany and both employed the ADI and the ADOS to identify cases. ${ }^{177}$ The interest in 5-HTT had arisen in relation to autism as part of a broader theory of psychological atypicality, in particular reports of its association with 'anxiety-related traits. ${ }^{178}$ Such traits had been observed in family members of individuals with autism and so hypotheses began to be drawn around this new way of thinking about psychological development as part of an autistic spectrum. However, by 1999, new studies emerged that debunked the association between 5-HTT and autism, in particular one US study 'generated from an ethnically heterogeneous group of Caucasian, Hispanics, African-Americans, and Asians'. Another joint UK and US study based on data from the International Molecular Study of Autism Consortium, and employing the ADI to measure 'type 1' autism, also showed no association. A joint Italian and US study of 'two ethnically' distinct samples found the same result, based on DSM criteria but not the ADI and ADOS. However, in 2001 an Israeli study claimed there was an association, using $\mathrm{ADI}$ and $\mathrm{ADOS}$ tools translated into Hebrew. ${ }^{179} \mathrm{~A}$ joint US and French venture from the same year claimed that the association between the promoter polymorphism of the serotonin transporter and autism did exist, with the short allele being more common in children who scored highest in the severity of 
the triad of impairments as measured in the $\mathrm{ADI}$, and the longer allele more common in children who scored lower, thus demonstrating a milder or more moderate version of the triad. ${ }^{180}$ Wing's triad of impairments, in particular as measured in $\mathrm{ADI}$, was being linked to discrete fragments of the human genome through major international research programmes. This was an obvious abstraction from the social and political context in which the idea of 'social impairment' was formed. Nevertheless, the concept enabled new international communities to form, now focused simply on creating reproducible studies.

Genetic studies of autism were, at one point, used to invalidate environmental hypotheses, in particular the MMR theory. ${ }^{181}$ However, as research developed, the complexities of environment and gene interaction were realised, again, helping to expand the domain of the autistic spectrum. Some other early human molecular genetic studies of autism examined the promoter region of the dopamine $\beta$-hydroxylase gene, finding that the mothers of autistic children seemed to show abnormalities that may create a 'suboptimal uterine environment.' ${ }^{182}$ The dopamine hypothesis emerged from other biochemical studies of depression and other mental illness in adults, much as the serotonin hypothesis had done. Many other candidate genes in autistic people themselves were suggested from the late 1990s. For example, candidate genes on chromosome 15q11-13 (a region associated with Prader-Willi and Angelman syndrome) were examined at the turn of the century because it was found to be a common site for chromosomal abnormalities in autism, although early studies found little conclusive results. Nevertheless, international scholars jumped at the prospect of contributing to this work, with research on 15q11-13 issuing from Brazil, India and elsewhere. ${ }^{183}$

In 2006, Sabhrangshu Guhathakurta from the Manivokas Biomedical Research and Diagnostics Centre, Kolkata, published the results of a major autism study funded by the Council of Scientific and Industrial Research, Government of India. The research had brought together colleagues from across India to produce a study of 5-HTT in an Indian population. They argued that disagreement between reports on 5-HTT could be explained because of 'the complexity of serotoninergic neurotransmitter system where the synthesis, uptake, neurotransmission, metabolism and regulation of 5-HTT involve an array of proteins and the effect of each protein may contribute to the pathology. ${ }^{184}$ Indeed, 
such studies highlighted the complexity of the genetic data and dissolved the idea that a single gene for autism would be discovered. Yet, as with all genetic studies, the belief still held that genetic research, based on the autistic spectrum, would yield results in time. As Guhathakurta put it, 'A systematic investigation taking into account the varying spectra of impairments in interaction, communication, and behavior might prove to be more appropriate to clarify the present confusing results. ${ }^{185}$ However, the more research that was conducted, the more complex the results became. A 2007 study by Guhathakurta and other Indian researchers found no association between autism and glutamate receptor 6 gene, GluR6 or GRIK2, polymorphisms, despite the fact that findings from the Paris Autism Research International Sibpair (PARIS) Study and a major study in China had found that there was an association. ${ }^{186}$ All of these studies used DSM-IV or ICD 10 in the diagnosis of cases, and thus Wing's essential triad. Although they had different findings, Guhathakurta and others argued this was all the more reason to conduct even more studies to see if an association could be drawn from even larger population samples from the genetic profiles of autistic people across the globe.

Neuroscientific research on humans has been paralleled by new explorations into 'autism' and 'social impairment' in other animals, such as mice, in order to assist large-scale testing of genetic atypicalities and enabling genetic research to thrive. The conceptual problems of identifying autism in a mouse were usually sidelined by wider claims that genetic correlates had been discovered. ${ }^{187}$ Although there is currently no version of the $\mathrm{ADI}$ or $\mathrm{ADOS}$ for mouse or rat populations, international researchers have tried to categorise behaviours associated with the triad of impairments as these exist in rodents. In 2013, Marcus Wöhr from the Philipps-University of Marburg, and Maria Luisa Scattoni from the Instituto Superiore di Sanità in Italy, argued that if tested in an open field or observation box, rodents with 'autism' would demonstrate the social deficits of the triad through restricted 'social interaction' and 'social play'. They would demonstrate the communication deficits of the triad through lack of scent marking, lack of female-induced and interactioninduced ultrasonic vocalisations. Finally, 'motor stereotypes', 'repetitive self-grooming', repetitive marble-burying and 'restricted exploration' demonstrated the stereotypic and repetitive behaviours of Wing's triad of impairments. This was an attempt to synthesise approaches to 
mouse behaviour that had been focused on measuring abnormal social interaction, by creating a model that encompassed the whole triad. ${ }^{188}$ A collaborative German and French project also developed an 'autism severity score' to measure the degree of autism in mice by measuring the degree of their abilities in nest-making and other activities and the degree of any atypical behaviours such as excessive marble-burying. ${ }^{189}$ These standardised approaches helped cement the idea that rodents can suffer from autism. The problems of anthropomorphism and of delimiting the nature of the imagination in humans are glossed over in these attempts to bring the autistic spectrum to the animal world and thus to rethink early animal development.

In the USA, autism genetic research in human and animal forms is particularly thriving, largely due to the efforts of parental organisations, as Chloe Silverman has pointed out, in particular the National Alliance for Autism Research (NAAR), founded in 1994, and the Cure Autism Now (CAN) foundation, founded in 1995. CAN established the Autism Genetic Research Exchange (AGRE), a gene repository for families with two or more members with an autism diagnosis. The repository attracted many parents who sought to speed up genetic research. ${ }^{190}$ In 2003, the NAAR launched the Autism Genome Project (AGP) consortium that brought together North American and European researchers in an effort to improve genetic research into autism. In 2005, NAAR merged with a new organisation, Autism Speaks, and in 2006, CAN also merged with them. Autism Speaks is now the dominant autism science and advocacy organisation internationally, serving to facilitate and fund research and awareness. ${ }^{191}$ Although the AGP did not match its initial hopes of finding a single gene mutation, it has since served as an exemplar model to encourage scientific exchange of data and has also encouraged the growth of new theories surrounding the role that genes may play in the development of all psychological conditions in childhood. It has also encouraged a greater understanding of the complexity of gene and environment interactions in the formation of all developmental disorders. More recently, genetic studies have taken into account a wider, and comprehensive range of childhood developmental conditions. This merely confirms that autism is a central concept of child development and is associated with many different conditions, and debunks the idea that it is a unique disorder. For example, a 2012, a study by D. Moreno-De-Luca, Emory State 
University, and colleagues from across the USA analysed data from 35,516 cases using two large datasets, namely Signature Genomics and the International Standards for Cytogenomic Arrays Consortium, the latter of which includes data from the Autism Genetic Resource Exchange, the Autism Genome Project and the Simons Simplex Collection. Moreno-De-Luca reported that if children with a range of developmental delays, intellectual disability, ASD or related problems from this dataset were included, then around 1 in every 553 showed deleterious recurrent deletions in 15q11-13. Further analysis of the datasets exploring ASDs specifically found deleterious recurrent deletions in only ten regions that showed statistical significance, the most significant being 16p11.2, although even this showed a frequency, in total autistic spectrum conditions, of 1 in $304 .{ }^{192}$ This only confirmed that wider samples relating to numerous conditions in childhood were the best way to take genetic research, thus ultimately pulling it further from the initial attempts to find genes for 'autism. In early 2015, a team of researchers from Canada, USA, China and Sweden concluded that 'substantial genetic and clinical heterogeneity exists in ASD and that much larger surveys will need to be completed to completely understand the genetic architecture of ASD'. ${ }^{193}$ It would be hard to find a clearer advertisement for the idea of neurodiversity. In fact, genetic research has, in many ways, undermined the concept of the second autism that it was developed to support.

Even as early as 2007, Daniel Geschwind, from the neurogenetics programme at the University of California, and Pat Levitt, from the Vanderbilt Kennedy Center for Research on Human Development, argued that autism was 'analogous to broad syndromes such as mental retardation', had multiple causes and was best considered as a 'heterogeneous, neurodevelopmental syndrome'. It was therefore better to think in terms of 'the autisms' rather than 'autism. ${ }^{194}$ In 2012, Christopher Gillberg, the enthusiastic supporter of the epidemiological method for autism and Asperger's research, famously published The Autisms to highlight varied aetiology and the multiple ways in which the triad of impairments can manifest itself across the entire gamut of autistic spectrum disorders. This tendency to think broadly around the category has been supported by genetic research that is also problematising the idea that there is a simple medical problem called 'autism' or even 'autistic spectrum disorder.' ${ }^{\prime}$ 
Although this study and others do not claim that there is unique genetic disorder called 'autism', finding instead multiple variations and differences in the data, they have generally stopped short of completely abandoning the concept of the second autism. Of course, it would be virtually impossible to do so given its extensive presence in the fields of politics and social justice. Autism thus continues to garner political and scientific support, even as its fundamental diagnostic criteria are challenged. However, this project to identify the genetic substructure to autism is likely to represent the pinnacle, and perhaps even the end, of the second autism, as challenges to this definition continue to grow.

The reason why the phenotypical model for autism has been so zealously sought is because it is the only model that measures social interaction and its atypicalities through genetic phenotypes. It is also the replacement for 'human relations' psychology and so researchers desperately seek the complex architecture of the human genome to support it. If any new researchers want to think about what is abnormal or unusual in the development of human relationships, they no longer look to anthropology or psychoanalysis, which are often regarded as obsolete human sciences. Instead they think about autism and its development in humans, as mapped in the human genome, as quantified in epidemiological studies all over the world, as discussed on global health platforms. These new models used to investigate and explore the second autism as the kernel of theories of child identity and social development are based on statistical, epidemiological and biomedical sciences that are vastly different from those used to investigate the first autism. The approach to children as cases, and the approach to 'data' produced by those children, has changed so dramatically that earlier sciences and approaches to human development and human relationships have been almost entirely forgotten. New epidemiological definitions of autism have redefined the way we think about child development and human relations. Yet these approaches have historical roots and historical origins. The fact that this particular model of children's developmental atypicalities was formulated via British epidemiological sciences from the 1960 s to the late 1970 s is actually relevant to genetic researchers who are now busy searching with common diagnostic tools. 


\section{The Global Autism}

Many international autism researchers have thought about infant and child cognitive development, along with its 'deficits' and 'impairments', using cognitive models derived from British psychological models from the 1960 s to the 1980 s that used epidemiological methods to measure autism and the autistic spectrum. Although much genetic and environmental research has reinforced the claim that there is no such thing as 'autism' and no genetic components that correlate with 'the autistic spectrum', so much has been invested in studying the autistic spectrum, and the idea of the spectrum been so convincing and powerful in eradicating earlier psychological models of child development, that it is now virtually impossible to view any differences or atypicalities in children's social development through any other lens. We have reached a point where genetic research, and other neuroscientific research in autism, promises to provide answers to all problems and questions raised about different kinds of social engagement. So many studies have been conducted, so much data collected, there is no way that neuroscientists and psychologists could really turn their back on this idea. Not only research programmes, but also NGOs, and national and international laws all now support the idea of the 'autistic spectrum'.

Nevertheless, by examining the historical assumptions that the theory of the autistic spectrum psychology rests upon, and the conceptual frameworks that have provided its base, it is possible to see a more multifaceted historical model that has produced this concept. Unique 'styles of reasoning' that focused on autism as an epidemiological object have shaped our current understanding of autism. Not only have these models had an impact on autism research, they have also had a major impact on children's rights and on education, health and welfare policy. Autism is a defining concept that has structured ideas of what child development means, and how different social and legal agencies should respond to it. Changes in the meaning of autism have thus also had the capacity to transform human relations and social structures in the national and international contexts where the concept has been employed. International scientific communities, education, health, and social care systems have now been built up around this concept of autism and it is hard to imagine how they could now be dismantled. 


\section{Notes}

1 B. Jackson, 'The think-tank archipelago'.

2 Rose, Powers of Freedom; Rose, 'The death of the social?'.

3 Cockburn, Rethinking Children's Citizenship.

4 Hendrick, Child welfare and Social Policy.

5 Detrick et al., The United Nations Convention on the Rights of the Child.

6 KCL/BCGC: Brixton CGU Annual Reports 1980s: Brixton CGU Annual Report, 1984, p. 7.

7 Rutter et al., 'Children of West Indian immigrants'.

8 Littlewood, 'From categories to contexts'; Kleinman, 'Depression, somatization and the "new cross-cultural psychiatry".

9 Lotter, 'Childhood autism in Africa'.

10 Lotter, 'Childhood autism in Africa', 232.

11 Lotter, 'Childhood autism in Africa', 239.

12 Lotter, 'Cross cultural perspectives on childhood autism'.

13 E.g. Fanon, The Wretched of the Earth.

14 Lotter, 'Childhood autism in Africa', 231.

15 Brask, 'A prevalence investigation of childhood psychosis'; Brask, quoted in L. Wing et al., 'The prevalence of early childhood autism'; L. Wing et al., 'The prevalence of early childhood autism'; Treffert, 'Epidemiology of infantile autism'; L. Wing, 'The definition and prevalence of autism'.

16 Volkmar et al., 'Age of recognition of pervasive developmental disorder'; Fisher et al., 'A treatable language disorder'; Anderson, 'Monoamines in autism'.

17 Stengal, 'A comparative study of psychiatric classifications'; Miller, 'The problem of classification in child psychiatry'.

18 Rutter et al., Multi-Axial Classification of Child Psychiatric Disorders.

19 Klerman et al., 'A debate on DSM-III'; Spitzer, 'Values and assumptions in the development of DSM-III and DSM-III-R', 356; Shaffer, 'Classification and categorisation revisited'.

20 Mayes and Horwitz, 'DSM-III and the revolution in the classification of mental illness', 249, 263.

21 E.g. Wilson, 'DSM-III and the transformation of American psychiatry'; Shorter, A History of Psychiatry, p. 302.

22 Rutter, 'Diagnosis and definition of childhood autism', 156.

23 American Psychiatric Association [APA], Diagnostic and Statistical Manual of Mental Disorders: DSM-III; Lindsay, Screening for Children with Special 
Needs, pp. 88-89; Volkmar, Handbook of Autism and Pervasive Developmental Disorders, p. 15.

24 Porter, London, p. 354.

25 Waterhouse et al. 'Pervasive developmental disorders and schizophrenia occurring in childhood'.

26 Waterhouse et al., 'Pervasive developmental disorders: From DSM-III to DSM-III-R'

27 E.g. Becker and Thoman, 'Rapid eye movement storms in infants'; Calame et al., 'Psychological and neurodevelopmental outcome of high risk newborn infants'; Astbury et al., 'Neonatal and neurodevelopmental significance'.

28 Rutter, 'Autistic children: Infancy to adulthood', quoted in Denckla, 'New diagnostic criteria for autism and related behavioral disorders', 221.

29 Mayes and Horwitz, 'DSM-III and the revolution in the classification of mental illness'.

30 Denckla, 'New diagnostic criteria for autism and related behavioral disorders'.

31 American Psychiatric Association, Diagnostic and Statistical Manual of Mental Disorders: DSM-III-R.

32 Waterhouse et al., 'Pervasive developmental disorders and schizophrenia occurring in childhood'.

33 Sanua, 'Is infantile autism a universal phenomenon?', 167, 172, 173.

34 Other collaborators were Sarnoff Mednick from the University of Southern California and Fini Schlusinger, director of the Psykologisk Institut at Kommunehospitalet, Copenhagen.

35 Raine et al., 'Cohort profile: The Mauritius child health project'.

36 E.g. The Danish State Department for Technical Collaboration with Developing Countries, the British Medical Research Council, the Danish International Aid Organisation, the Wellcome Trust, the Leverhulme Trust, the Mental Health Foundation, the Ford Foundation, the Scottish Rite, the National Institute of Mental Health (US), and the National Institute of Child Health and Development (US).

37 National Autistic Society (NAS) Archives NAS archives: Box 4. File: Autism Europe Publications/Charters/Leaflets. Autism Europe IAAE leaflet 1984.

38 NAS archives: Box 4. File: Autism Europe Publications/Charters/Leaflets. Link Autism Europe Magazine Special 20th Anniversary August 2003.

39 NAS archives: Box 2: Autism Europe. 3rd European Congress 6-8 May 1988. 
40 Baron-Cohen and Bolton, Autism: The Facts, Appendix.

41 Baron-Cohen and Bolton, Autism: The Facts, appendix; Daley, 'The need for cross-cultural research'.

42 Gillberg et al., 'Psychiatric disorders in mildly and severely mentally retarded urban children and adolescents'.

43 Bryson et al., 'First report of a Canadian epidemiological study of autistic syndromes', 443.

44 Chamak, 'Autism and social movements'.

45 Cialdella and Mamelle, 'An epidemiological study of infantile autism in a French department (Rhône)', 172.

46 Sugiyama and Abe, 'The prevalence of autism in Nagoya, Japan'.

47 Steffenburg and Gillberg, 'Autism and autistic-like conditions in Swedish rural and urban areas'.

48 Gillberg et al., 'Infantile autism in children of immigrant parents'; Gillberg et al., 'Is autism more common now than ten years ago?'; Gillberg, 'Maternal age and infantile autism'.

49 Hayward, 'Medicine and the mind'.

50 Kramer, Listening to Prozac; Hacking, Rewriting the Soul; Olfman, Bipolar Children.

51 Kramer, Listening to Prozac.

52 Le Couteur et al., 'Autism diagnostic interview', 363.

53 Rutter and Schopler, 'Autism and pervasive developmental disorders', 163.

54 Schopler et al., The Childhood Autism Rating Scale (CARS); Freeman et al., 'The behavior observation scale for autism'; Freeman et al., 'Behaviour assessment of the syndrome of autism'; Krug et al., 'Behaviour checklist'; Volkmar et al., 'An evaluation of the autism behavior checklist'; Ruttenberg et al., Behavioral Rating Instrument for Autistic and Other Atypical Children.

$55 \mathrm{MHCP} / \mathrm{A}$. Completed ADI form, 1987: Social Development First Five Years. Affection p. 29.

$56 \mathrm{MHCP} / \mathrm{A}$. Completed ADI form, 1987.

57 Lord et al., 'Autism diagnostic observation schedule', 187.

$58 \mathrm{MHCP} / \mathrm{A}$. Material on ADI and ADOS. Commentary on ADI (R) training tapes, 1991, 'Social Development and Play'. Example 3.

59 Interview with Uta Frith. Conducted by Bonnie Evans. 17 December 2014.

60 Murray, Representing Autism.

61 Morton, 'The origins of autism', 44, 47.

62 Frith, 'Autism', 114. 
63 Uta Frith Archive. BPS Media Release: Asperger's Syndrome: Eccentricity or Disability 30 August 1991.

64 O'Sullivan, 'Train spotters "may suffer from autism".

65 Sellin, In Dark Hours I Find My Way; Williams, Nobody Nowhere.

66 Sacks, An Anthropologist on Mars.

67 Newnham, 'News from nowhere?'.

68 Baron-Cohen and Bolton, Autism: The Facts, p. 10.

69 Happe, Autism, pp. 5-6.

70 L. Wing, 'Autistic spectrum disorders', 312.

71 L. Wing, 'Autistic spectrum disorders'.

72 Ehlers and Gillberg, 'The epidemiology of Asperger syndrome'.

73 APA, Diagnostic and Statistical Manual of Mental Disorders: DSM-IV, p. 77.

74 Waterhouse et al., 'Pervasive developmental disorders: From DSM-III to DSM-III-R', 530. Baird et al., 'Autism is not necessarily a pervasive developmental disorder', 363.

75 E.g. Gillberg, 'Neurodevelopmental processes and psychological functioning in autism'; Trevarthen, 'Autism as a neurodevelopmental disorder'.

76 E.g. Whitmore et al., A Neurodevelopmental Approach to Specific Learning Disorders.

77 E.g. Leslie and Thaiss, 'Domain specificity in conceptual development'.

78 E.g. Losh and Piven, 'Social-cognition and the broad autism phenotype'; Campbell et al., 'Association of MET with social and communication phenotypes.

79 Wignyosumarto et al., 'Epidemiological and clinical study of autistic children in Yogyakarta, Indonesia'; Honda et al., 'Cumulative incidence and prevalence of childhood autism in children in Japan', 234.

80 Magnusson and Sæmundsen, 'Prevalence of autism in Iceland'.

81 NAS archives: Box 4. File: Autism Europe Publications/Charters/Leaflets. 'Building a Brighter Future' pamphlet, 10/9/97, p. 17.

82 Baird et al., 'A screening instrument for autism at 18 months of age'.

83 Centers for Disease Control and Prevention (CDC), Prevalence of Autism in Brick Township, New Jersey, 1998; Department of Health, 'Medical research council to re-examine autism'; Baird et al., 'A screening instrument for autism at 18 months of age'; Madsen et al., 'A population-based study of measles, mumps, and rubella vaccination and autism'; Scott et al., 'Brief report: Prevalence of autism spectrum conditions'; Yeargin-Allsopp et al., 'Prevalence of autism in a US metropolitan area'; Baird et al., 'Prevalence of disorders of the autism spectrum'; Kawamura et al., 'Reevaluating 
the incidence of pervasive developmental disorders'; Fombonne, 'Epidemiology of pervasive developmental disorders'.

84 Eyal et al., The Autism Matrix.

85 Wazana et al., 'The autism epidemic'; Leonard et al., 'Unpacking the complex nature of the autism epidemic'; Isaksen et al., 'Autism spectrum disorders'.

86 Fombonne, 'Epidemiology of pervasive developmental disorders'; Eyal et al., The Autism Matrix.

87 NAS archives: Box 2: File 'Autism on the Agenda'. 1993 International Conference on Autism agenda.

88 NAS archives: Box 2: File 'Autism on the Agenda': Autism on the Agenda, Leeds University, 8-10 April 1994.

89 NAS archives: Box 4. File: Autism Europe Publications/Charters/Leaflets. Statement to the European Council on the eve of the Luxembourg Jobs Summit. 18 November 1997.

90 NAS archives: Box 4. File: Autism Europe Publications/Charters/Leaflets. Code of Good Practice on Prevention of Violence against Persons with Autism, December 1998.

91 NAS archives: Box 4. File: Autism Europe Publications/Charters/Leaflets. Code of Good Practice on Prevention of Violence against Persons with Autism, December 1998, pp. 27-30, 55, 33.

92 NAS archives: Box 4. File: Autism Europe Publications/Charters/Leaflets. Code of Good Practice on Prevention of Violence against Persons with Autism, December 1998, p. 89.

93 NAS archives: Box 4. File: Autism Europe Publications/Charters/Leaflets: 'Describing Autism', booklet May 1992.

94 NAS archives: Box 4. File: Autism Europe Publications/Charters/Leaflets: Fax message from Anne Sophie (Parent) regarded European Summit on Employment. Message from Autism Europe to Commissioner Flynn 20/11/97.

95 NAS archives: Box 4. File: Autism Europe Publications/Charters/Leaflets. Notes on Autism Europe meeting 1998.

96 NAS archives: Box 2: File 'NAS Board and Council Minutes': WAO newsletter December 1999.

97 NAS archives: Box 2: File 'NAS Board and Council Minutes': Agenda of two-day autism conference for UNESCO, 17-18 May 2000.

98 NAS archives: Chief Executive Higashi File and Boston Visit File. The Higashi Experience, 1991; Report on a Visit by NAS to the Boston Higashi School, 5-9 November 1995. 
99 Wallace, 'Hope for shadow children'. NAS archives: Chief Executive Higashi File and Boston Visit File. Report on a Visit by NAS to the Boston Higashi School, 5-9 November 1995, p. 12.

100 NAS archives: Chief Executive Higashi File and Boston Visit File. Mooney, F 'Parents go Bust as "Rain Man” Children Suffer', cutting from Daily Express, 27 June 1990.

101 NAS archives: Chief Executive Higashi File and Boston Visit File: The International Autistic Research Organisation newsletter 1990, p. 8.

102 NAS archives: Research Papers and Info/Autism Europe Congress 2000. Summary of Early Intervention Conference 12 June 2001.

103 NAS archives: Research Papers and Info/Autism Europe Congress 2000. London Early Autism Project report, p. 1.

104 United Nations, Resolution 62/139 World Autism Day.

105 Autism Speaks, 'Autism Speaks launches unprecedented global autism public health initiative'. Author italics

106 Autism Speaks, 'Autism Speaks launches global action committee'.

107 Li et al., 'Prevalence of autism-caused disability among Chinese children'.

108 Bakare and Munir, 'Autism spectrum disorders (ASD) in Africa'.

109 Bakare et al., 'Prevalence of autism spectrum disorder among Nigerian children with intellectual disability', 517.

110 Eldin et al., 'Use of $\mathrm{m}$-chat for a multinational screening', 282.

111 Children of the Stars [documentary].

112 Sun et al., 'Prevalence of autism in mainland China, Hong Kong and Taiwan', 7.

113 Teixeira et al., 'Brazilian scientific output on autism spectrum disorders'.

114 Estecio et al., 'Molecular and cytogenetic analyses on Brazilian youths with pervasive developmental disorders'; dos Santos et al., 'Mthfr c677t is not a risk factor for autism spectrum disorders in South Brazil'.

115 Paula et al., 'Autism in Brazil: Perspectives', 5.

116 Gomes et al., 'Autism in Brazil: A systematic review'.

117 Rudra et al., 'Translation and usability of autism screening and diagnostic tools'

118 Divan et al., 'Challenges, coping strategies, and unmet needs'.

119 Igwe et al., 'Factors influencing knowledge about childhood autism', 44.

120 Kutchins and Kirk, Making Us Crazy.

121 NAS Archives: Research Papers and Info/Autism Europe Congress 2000: 'Landmark Ruling by the House of Lords', 27 July 2000. 
122 NAS Archives: Research Papers and Info/Autism Europe Congress 2000: press cutting, 'The Sincott Case', The Irish Times, 7 October 2000.

123 NAS Archives: Research Papers and Info/Autism Europe Congress 2000: Tony Holland et al., Report Commissioned by the Department of Health, 2000, p. 26.

124 J. Evans et al., Making a Difference.

125 Department for Education, Statistics (2012).

126 Reichow et al., 'Non-specialist psychosocial interventions'. BelloMojeed and Bakare, 'Improving treatment of children with autism spectrum disorder'.

$127 \mathrm{WHO}$, MhGAP Intervention Guide for Mental, Neurological and Substance Use Disorders.

128 Elsabbagh et al., 'Global prevalence of autism and other pervasive developmental disorders', 176.

129 Omigbodun, 'Developing child mental health services in resource-poor countries'.

130 Eldin et al., 'Use of m-chat for a multinational screening', 281; Igwe et al., 'Assessment of knowledge about childhood autism', 1; Li et al., 'Prevalence of autism-caused disability among chinese children'; Gomes et al., 'Autism in Brazil: A systematic review'; Balasubramanian et al., 'Genetic studies in children with intellectual disability'.

131 Wakefield et al., 'Retracted: Ileal-lymphoid-nodular hyperplasia', 637.

132 Wakefield et al., 'Retracted: Ileal-lymphoid-nodular hyperplasia', 641.

133 Murray, Autism, p. 81.

134 Horton, 'The lessons of MMR', 747.

135 Wakefield and Montgomery, 'Measles, mumps, rubella vaccine'; Wakefield, 'Enterocolitis, autism and measles virus'.

136 BBC, 'Blair stays mum on Leo and MMR'.

137 Murray, Representing Autism.

138 Wakefield, 'Statement from Dr Andrew Wakefield'.

139 Silverman, Understanding Autism.

140 Olmsted and Blaxill, Age of Autism; Kirby, Evidence of Harm.

141 B. Taylor et al., 'Autism and measles, mumps, and rubella vaccine'.

142 Kaye et al., 'Mumps, measles, and rubella vaccine and the incidence of autism? 
143 Dales et al., 'Time trends in autism and in MMR immunization coverage in California'.

144 Honda et al., 'No effect of MMR withdrawal on the incidence of autism'.

145 Fombonne et al., 'Pervasive developmental disorders in Montreal, Quebec, Canada'.

146 Heron et al., 'Thimerosal exposure in infants and developmental disorders', 583; Fombonne et al., 'Pervasive developmental disorders in Montreal, Quebec, Canada'; Madsen et al., 'Thimerosal and the occurrence of autism'; L. E. Taylor et al., 'Vaccines are not associated with autism'.

147 Waterhouse, 'Autism overflows', 273.

148 Silverman, Understanding Autism.

149 NAS Archive. Box 1. MMR. Sandra and Max Desorgher email to Malanie Landman, 'The Vaccine Issue, Humanity and Autism, a Common Causal Factor' 25 June 2002.

150 Rogers, 'Has enhanced folate status during pregnancy altered natural selection and possibly autism prevalence?'

151 Waldman et al., 'Autism prevalence and precipitation rates', 1027.

152 E.g. Volk et al., 'Residential proximity to freeways and autism in the charge study'; Schmidt et al., 'Prenatal vitamins, one-carbon metabolism gene variants, and risk for autism'; Brown et al., 'Maternal thyroid autoantibody and elevated risk of autism'; Gardener et al., 'Perinatal and neonatal risk factors for autism.

153 Shattuck, 'Diagnostic substitution and changing autism prevalence.'

154 Horwitz, Creating Mental Illness; Kutchins and Kirk, Making Us Crazy.

155 Healy, The Creation of Psychopharmacology.

156 Rutter and Folstein, 'A twin study of individuals with infantile autism', p. 234.

157 E.g. August et al., 'The incidence of cognitive disabilities in the siblings of autistic children'; Minton et al., 'Cognitive assessment of siblings of autistic children'.

158 Bolton et al., 'A case-control family history study of autism', 895 .

159 Bailey et al., 'Autism as a strongly genetic disorder'.

160 Gillberg and Svennerholm, 'Csf monoamines in autistic syndromes'.

161 Rutter, Bailey et al., 'Autism: Syndrome of definition'; Bolton et al., 'Genetic findings and heterogeneity in autism'.

162 M. Rutter et al., 'Autism and known medical conditions: Myth and substance', J Child Psychol Psychiatry 35, no. 2 (1994): 311-322. 
163 NAS archives: Box 2: File 'Autism on the Agenda': Autism on the Agenda, Leeds University, 8-10 April 1994. 'Medical Aspects of Autism' Dr Christopher Gillberg. Baron-Cohen et al., 'The autismspectrum quotient (AQ)'. Rutter, Bailey et al., 'Autism and known medical conditions'.

164 Baron-Cohen et al., 'The autism-spectrum quotient (AQ)'.

165 Frith, Autism: Explaining the Enigma.

166 Happe et al., 'Exploring the cognitive phenotype of autism'.

167 Baird et al., 'A screening instrument for autism at 18 months of age', 695.

168 Hollin and Pilnick, 'Infancy, autism, and the emergence of a socially disordered body'.

169 Baron-Cohen and Hammer, 'Parents of children with Asperger syndrome'; Gillberg, 'Clinical and neurobiological aspects of Asperger's syndrome.'

170 Rutter et al., 'A five to fifteen year follow up study of infantile psychosis'; Rutter, 'Diagnosis and definition'.

171 L. Wing, 'Asperger's syndrome: A clinical account'.

172 Baron-Cohen and Hammer, 'Is autism an extreme form of the male brain?'; Baron-Cohen et al., Prenatal Testosterone in Mind.

173 Baron-Cohen et al., Prenatal Testosterone in Mind.

174 For example: Goodenough, 'Interest in persons as an aspect of sex differences in the early years'; McGuinness and Pribram, 'The origins of sensory bias.

175 Geschwind and Galaburda, Cerebral Lateralization. See Baron-Cohen, 'The extreme male brain theory of autism'.

176 E.g. Nadesan, 'Autism and genetics'.

177 Cook et al., 'Evidence of linkage between the serotonin transporter and autistic disorder'; Klauck et al., 'Serotonin transporter (5-HTT) gene variants associated with autism?'.

178 Lesch et al., 'Association of anxiety-related traits'.

179 Zhong et al., '5-HTTLPR variants not associated with autistic spectrum disorders', 130; E. Maestrini et al., 'Serotonin transporter (5-HTT) and gamma-aminobutyric acid receptor subunit beta 3 (GABRB3) gene polymorphisms'; Persico et al., 'Lack of association between serotonin transporter gene promoter variants and autistic disorder'; Yirmiya et al., 'Evidence for an association'. 
180 Tordjman et al., 'Role of the serotonin transporter gene'.

181 Folstein and Rosen-Sheidley, 'Genetics of autism.

182 Robinson et al., 'Genetically determined low maternal serum dopamine beta-hydroxylase levels'.

183 Silva et al., 'Tetrasomy 15q11-q13 identified by fluorescence in situ hybridization'; Cook et al., 'Linkage-disequilibrium mapping of autistic disorder'; Moreno-De-Luca et al., 'Using large clinical data sets to infer pathogenicity'.

184 Guhathakurta et al., 'Serotonin transporter promoter variants', 32.

185 Guhathakurta et al., 'Serotonin transporter promoter variants', 32.

186 Shuang et al., 'Family-based association study'; Jamain et al., 'Linkage and association of the glutamate receptor 6 gene with autism. Dutta et al., 'Glutamate receptor 6 gene (GLuR6 or GRIK2) polymorphisms in the Indian population'.

187 Lee et al., 'Impairment of social behavior and communication'.

188 Wöhr and Scattoni, 'Behavioural methods used in rodent models of autism spectrum disorders'

189 El-Kordi et al., 'Development of an autism severity score for mice'.

190 Silverman, Understanding Autism, p. 156.

191 Silverman, Understanding Autism, pp. 158-159.

192 Moreno-De-Luca et al., 'Using large clinical data sets to infer pathogenicity'.

193 Yuen et al., 'Whole-genome sequencing of quartet families with autism spectrum disorder', 185-186.

194 Geschwind and Levitt, 'Autism spectrum disorders', 103.

195 Coleman and Gillberg, The Autisms; Powell and Monteggia, The Autisms. 